Review

\title{
The environment and male reproduction: The effect of cadmium exposure on reproductive function and its implication in fertility
}

\author{
Cristina de Angelis ${ }^{a}$, Mariano Galdiero ${ }^{a}$, Claudia Pivonello ${ }^{b}$, Ciro Salzano ${ }^{b}$, \\ Daniele Gianfrillic ${ }^{c}$ Prisco Piscitelli ${ }^{a}$, Andrea Lenzi ${ }^{c}$, Annamaria Colao ${ }^{b}$, \\ Rosario Pivonello ${ }^{\mathrm{b}, *}$ \\ a I.O.S.E COLEMAN Srl, Naples, Italy \\ b Dipartimento di Medicina Clinica e Chirurgia, Sezione di Endocrinologia, Università "Federico II" di Napoli, Naples, Italy \\ c Dipartimento di Medicina Sperimentale, Università di Roma "La Sapienza", Rome, Italy
}

\section{A R T I C L E I N F O}

\section{Article history:}

Received 8 December 2015

Received in revised form 11 July 2017

Accepted 26 July 2017

Available online 1 August 2017

\section{Keywords:}

Environment

Cadmium

Heavy metals

Male reproduction

Fertility

Endocrine disruptors

Semen quality

Testosterone

\begin{abstract}
A B S T R A C T
Cadmium is an environmental pollutant known as endocrine disruptor. Testis is particularly susceptible to cadmium, and testis injury occurs at high but even low levels of exposure. Cadmium reproductive toxicity is mediated by multiple mechanisms, including structural damage to testis vasculature and bloodtestis barrier, inflammation, cytotoxicity on Sertoli and Leydig cells, oxidative stress mainly by means of mimicry and interference with essential ions, apoptosis, interference with selected signaling pathways and epigenetic regulation of genes involved in the regulation of reproductive function, and disturbance of the hypothalamus-pituitary-gonadal axis. The current review outlines epidemiological observational findings from environmental and occupational exposure in humans, and reports experimental studies in humans and animals. Lastly, a focus on the pathogenetic mechanisms of cadmium toxicity and on the specific mechanisms of cadmium sensitivity and resistance, particularly assessed in animal models, is included. Despite convincing experimental findings in animals and supporting evidences in humans identifying cadmium as reproductive toxicant, observational findings are controversial, suffering from heterogeneity of study design and pattern of exposure, and from co-exposure to multiple pollutants.
\end{abstract}

(c) 2017 Elsevier Inc. All rights reserved.

\section{Contents}

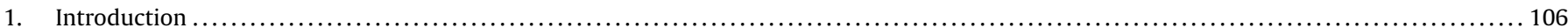

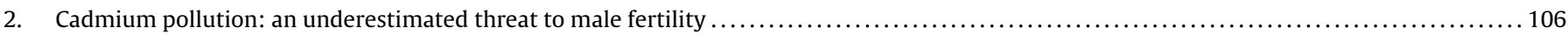

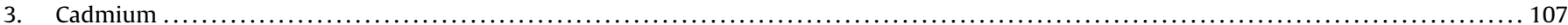

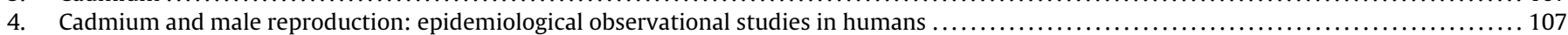

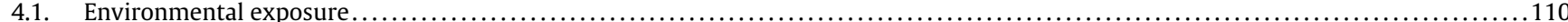

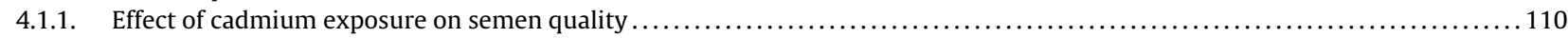

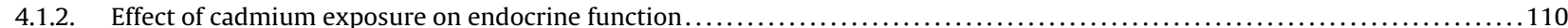

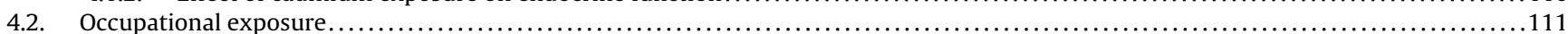

Abbreviations: Cd, cadmium; Zn, zinc; Cu, copper; $\mathrm{CdCl}$, cadmium chloride; bCd, whole blood Cd; bpCd, blood plasma Cd; sCd, serum Cd; spCd, seminal plasma Cd;

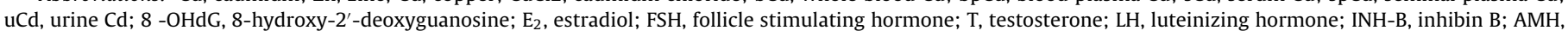

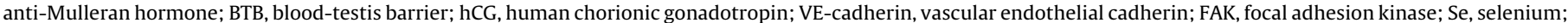

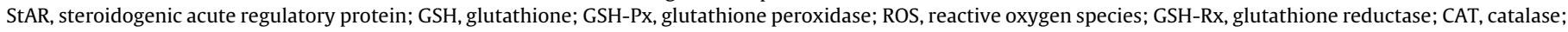

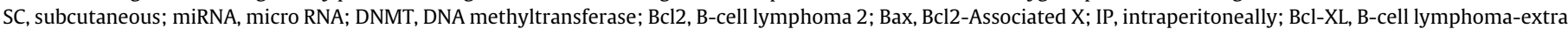
large; UPS, ubiquitin proteasome system; SAPK/JNK, stress-activated protein kinase/c-Jun N-terminal kinase; MTs, metallothioneins.

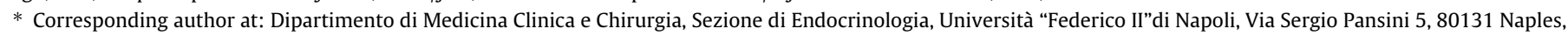
Italy.

E-mail addresses: cristinadeangelis83@hotmail.it (C. de Angelis), mariano.galdiero@gmail.com (M. Galdiero), claudia.pivonello@unina.it (C. Pivonello), cirosalzano89@gmail.com (C. Salzano), daniele.gianfrilli@uniroma1.it (D. Gianfrilli), prisco.piscitelli@tiscali.it (P. Piscitelli), andrea.lenzi@uniroma1.it (A. Lenzi), colao@unina.it (A. Colao), rosario.pivonello@unina.it (R. Pivonello). 


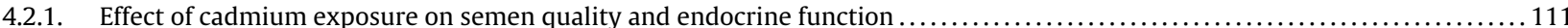

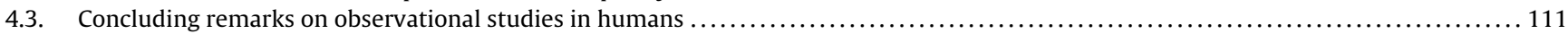

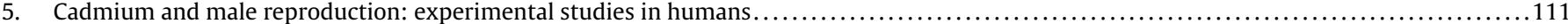

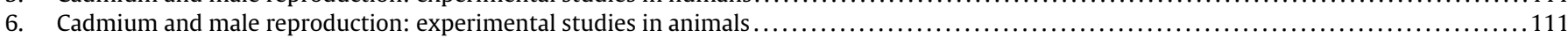

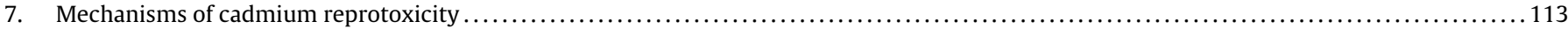

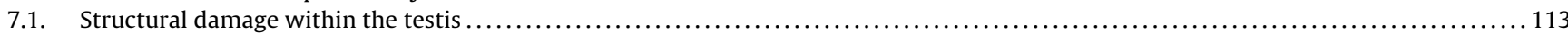

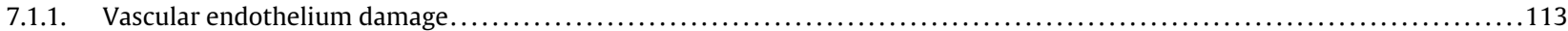

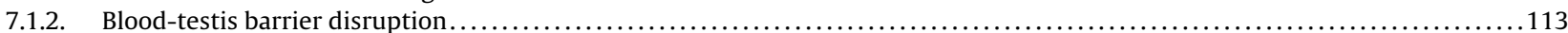

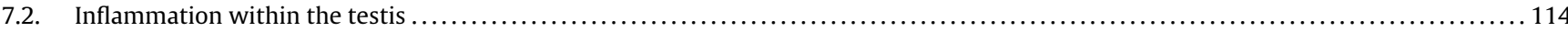

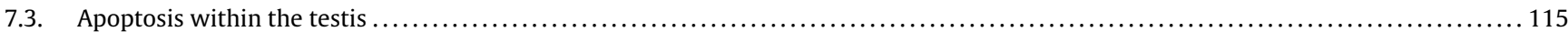

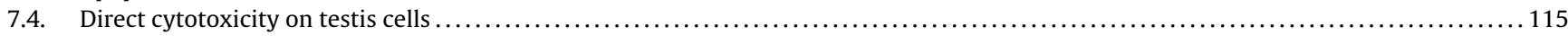

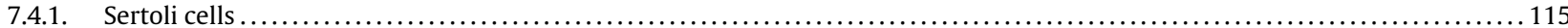

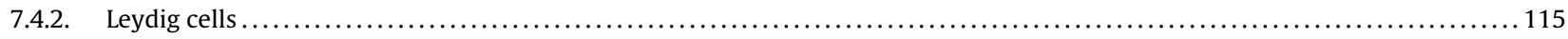

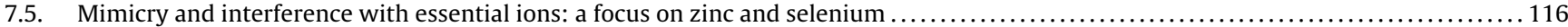

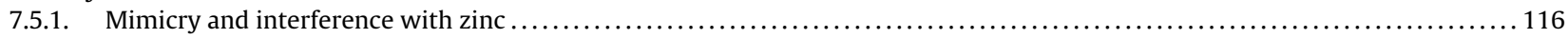

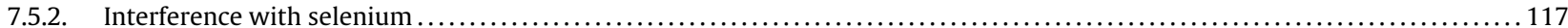

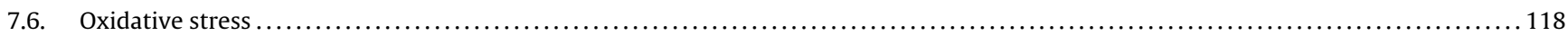

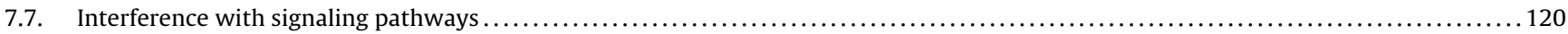

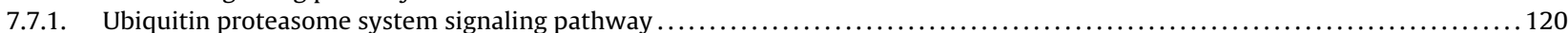

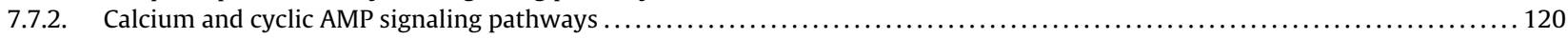

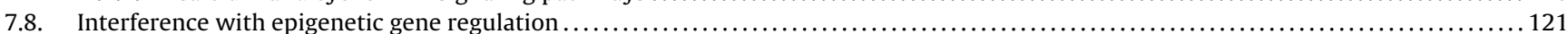

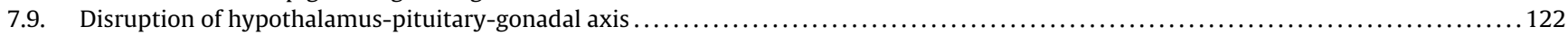

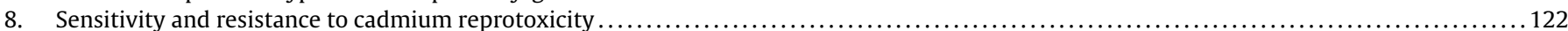

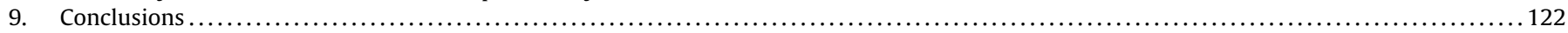

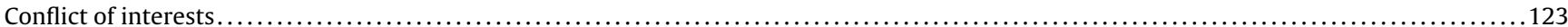

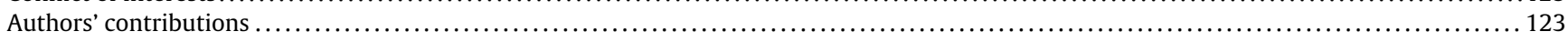

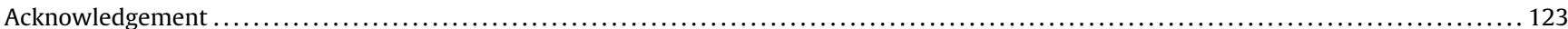

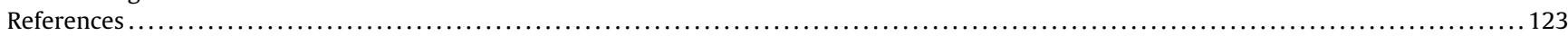

\section{Introduction}

A significant trend towards a worldwide decline in human fertility has been reported by international literature over the last five decades [1]; the progressive deterioration of couple fertility cannot be justified exclusively by changes in lifestyle (increase in women occupational rate, increase in women age at pregnancy), prevention of undesired parenthood (use of contraceptives, intentional abortions), or economic issues (decrease of income, increase of expense). A significant overall decline in male fertility, consequence of a progressive impairment of semen quality, was reported since early '90s, in a metanalysis of studies published between 1938 and 1991 [2]. Nevertheless, a recent re-analysis of the same studies, revealed heterogeneous results, mainly attributable to marked geographical variations in semen quality [3]. These conflicting and inconclusive results suggested the hypothesis of a possible impact of local persistent environmental pollution on male fertility [4]. Therefore, the contribution of concurrent, global and local factors, should be taken into account to explain the differences among the studies. Environmental exposure to toxic pollutants, which are present in the background ambience, as well as occupational exposure to specific toxic pollutants, which are consequence of jobrelated activities, have been demonstrated to negatively affect male fertility in humans $[5,6]$.

Heavy metals represent one of the most common categories of pollutants in the environment. Heavy metals are nearly ubiquitous, being released in the environment mainly by anthropic emission into the biosphere due to their wide use in industry, and represent a threat to human health, because of their long-term persistence in the environment and accumulation in the organic matter (bio-accumulation). Although a large body of evidence on the negative role of heavy metals on reproduction has been provided by experimental preclinical animal studies, little experimental clinical investigation has been performed in humans, with limitation to experimental studies on spermatozoa. Moreover, the translation of the results of in vivo studies from animals to humans is challenging: a precise correspondence between experimental dosage and the real environmental or occupational exposure in humans, as well as the relevance to humans of the length of experimental animal exposure, have not been fully established. Therefore, animal findings are not strictly applicable to humans, and may not be completely useful for a reliable risk assessment of exposure in humans. Lastly, the interpretation of epidemiological observational studies on heavy metals in humans is often complicated by confounding variables, such as smoking habits, and by the simultaneous exposure to multiple environmental pollutants exerting toxic effects on the male reproductive system (reprotoxicity), including bisphenols, dioxins, phthalates, pesticides, solvents, and additional hazardous compounds.

Cadmium $(\mathrm{Cd})$ has been repeatedly proven to be one of the major heavy metal exerting reprotoxicity in the male.

\section{Cadmium pollution: an underestimated threat to male fertility}

Cd pollution has become a real concern in industrialized and, especially, rapidly industrializing countries, because of the sustained pace of industrial activities, which represent one of the main sources of $\mathrm{Cd}$ production, that has been progressively rising during the decades, therefore arousing the interest on Cd-related health harm. The international literature has given a strong evidence of severe reprotoxicity driven by diverse patterns of $\mathrm{Cd}$ exposure; therefore, $\mathrm{Cd}$ has to be considered as a current menace to male fertility, and can be considered an important agent of reprotoxic pollution, deserving specific scientific insights.

The current review discusses the detrimental effects of Cd exposure on male fertility, by providing an overview of epidemiological observational studies in humans, and by reporting experimental studies in humans and animal models. The pathogenetic molecular mechanisms underlying the effects of $\mathrm{Cd}$ exposure on male reproductive system are critically discussed in a specific section, which reports the major findings in humans and animals, cathegorized by type of pathogenetic mechanism. 


\section{Cadmium}

$\mathrm{Cd}$, in its pure form, is a soft silver-white metal, which is present in the earth crust in association with multiple different metals; Cd is indeed extracted as a secondary product, during the processing of different metals, such as zinc ( $\mathrm{Zn})$, lead $(\mathrm{Pb})$, or copper $(\mathrm{Cu})$ [7]. The presence of $\mathrm{Cd}$ and $\mathrm{Cd}$ compounds in the environment is a consequence of both natural and anthropic processes. Natural sources of Cd include volcanic activity, weathering consumption of rocks, sea aerosols, forest fires and mobilization from soils and landfills [7]. As a derivative of anthropic activities, $\mathrm{Cd}$ and $\mathrm{Cd}$ compounds, such as $\mathrm{Cd}$-chloride $(\mathrm{CdCl} 2), \mathrm{Cd}$-acetate and $\mathrm{Cd}$-carbonate, derive from batteries, pigments, plastic stabilizers, pesticides and fertilizers, and photovoltaic devices, as well as from rubber processing, galvanization process, fossil combustion and waste incineration [7]. In recent years, safety regulations restricting Cd usage, particularly in the European Union, were introduced, due to concerns on the toxicity of Cd and Cd compounds [8]. Airborne particles of Cd and Cd compounds are transported and deposited in soil and water; mean total Cd concentrations in the air depend on the proximity to industrial source and might range between $0.1 \mathrm{ng} / \mathrm{m}^{3}$ up to $100 \mathrm{ng} / \mathrm{m}^{3}$, in remote areas and at source of emission, respectively [8]. Mean $\mathrm{Cd}$ concentrations in ocean range from $<5$ to $110 \mathrm{ng} / \mathrm{L}$, and are primarily due to natural weathering and erosion phenomena, and to atmospheric fall-out from both natural and anthropic emissions [8]. Sediment Cd concentrations have been reported to range from $0.03-1 \mathrm{mg} / \mathrm{kg}$ in marine sediments to up to $5 \mathrm{mg} / \mathrm{kg}$ in river and lake sediments, whereas average Cd concentration in soil is about $0.1-0.2 \mathrm{mg} / \mathrm{kg}$, although $>1 \mathrm{mg} / \mathrm{kg}$ concentrations have been measured in the soil near smelters and industrialized areas [8]. Cd bioaccumulates in the organic matter by entering the food chain [8] .

The exposure to $\mathrm{Cd}$ might be classified according to the target population and source of exposure; the general population is subjected to environmental exposure to relatively low concentrations of Cd commonly found in the background environment, whereas professionals manipulating $\mathrm{Cd}$ for job-related activities are subjected to occupational exposure to high concentrations of Cd [7]. Among environmentally exposed population, tobacco smokers are the most exposed subjects, since tobacco leaves accumulate large amounts of $\mathrm{Cd}$, making tobacco smoke the main source of $\mathrm{Cd}$ in smokers [7]. Indeed, it has been estimated that smokers are exposed to about $1.7 \mu \mathrm{g}$ of $\mathrm{Cd}$ per cigarette, $10 \%$ of which is inhaled, therefore, smokers absorb about $1-3 \mu \mathrm{g}$ Cd from smoking one pack of cigarettes per day; as a consequence $\mathrm{Cd}$ body charge in smokers is approximately double than in non-smokers [7,8]. Non-smokers are exposed to Cd by dietary intake of contaminated food (particularly cereals and grains, leafy vegetables, potatoes and offal) and contaminated water, and vegetarians intake of $\mathrm{Cd}$ from food is almost double, compared to non vegetarians $[7,8]$. In most countries, the average daily intake of $\mathrm{Cd}$ from food is between $0.1-0.4 \mu \mathrm{g} / \mathrm{kg}$ body weight [8]. Cd may also be perfused in alcoholic beverages, although alcoholic beverages consumption represents a significant source of metals only in heavy drinkers [9]. In the general population, blood plasma $\mathrm{Cd}(\mathrm{bpCd})$ concentration is within the range of 0.4-1 $\mu \mathrm{g} / \mathrm{L}$ in non-smokers and 1.4-4 $\mu \mathrm{g} / \mathrm{L}$ in smokers; nevertheless, higher concentrations have been reported in environmentally contaminated areas $(>10 \mu \mathrm{g} / \mathrm{L})$ [8]. The occupational exposure occurs almost exclusively by inhalation of Cd-polluted fumes or dust and by ingestion through dust-contaminated hands $[7,10]$. In occupationally exposed subjects, bpCd concentration might be up to 50 $\mu \mathrm{g} / \mathrm{L}$ [8]. Independently from the dietary Cd uptake, women seem to be more prone to Cd-related health effects, suggesting that a gender difference might exist in the susceptibility to Cd toxicity or in the body burden of $\mathrm{Cd}$, probably because of differences in Cd absorption $[11,12]$. Indeed, the gastrointestinal absorption of dietary Cd (about $5 \%$ in men and equal or more than $10 \%$ in women) varies among individuals and is influenced by dietary intake of essential nutrients, including iron (Fe), $\mathrm{Zn}$ and selenium (Se) [13-15]. Cd concentration in blood is a marker of both recent and cumulative exposure, whereas urinary concentration mainly mirrors cumulative exposure $[7,8]$. The estimated biological half-life of $\mathrm{Cd}$ is very long, ranging from 10 to 40 years in humans [7], and the clearance of Cd is very low, since about $0.007 \%$ and $0.009 \%$ of $\mathrm{Cd}$ body burden is excreted in urine and feces, respectively, per day $[7,8]$; consequently, Cd progressively accumulates in the liver and in the kidney, primary targets of Cd toxicity showing the earliest effects of $\mathrm{Cd}$ intoxication, but also in ovaries and placenta in women, as well as in testis, epididymis and, consequently, semen, in men [16-21].

The following sections report the results of epidemiological observational studies on male fertility in humans with environmental and occupational exposure to $\mathrm{Cd}$, and report the results of experimental studies in humans, which are limited to in vitro studies describing the effects of Cd treatment on spermatozoa, and experimental studies in animals, which are represented by in vivo studies investigating the effects of $\mathrm{Cd}$ exposure on male reproductive function, including development of reproductive system, endocrine function, spermatogenesis and semen quality, as well as fertility potential. Lastly, the current review discusses the pathogenetic molecular mechanisms underlying $\mathrm{Cd}$ reprotoxicity, which have been mainly uncovered in experimental in vitro, ex vivo and in vivo studies in animals, although some supporting evidences from observational studies and experimental studies are reported in humans; the entire series of experimental studies is critically discussed in a dedicated section of the current review, which reports the major findings in humans and animals, cathegorized by type of pathogenetic mechanism. A dedicated section on the mechanisms driving Cd sensitivity and resistance in the testis, is finally included in current review.

\section{Cadmium and male reproduction: epidemiological observational studies in humans}

The epidemiological observational studies describing the relationship between $\mathrm{Cd}$ exposure and male reproduction are cathegorized into two groups: studies on male subjects deriving from the general population with environmental exposure, and studies on male subjects with occupational exposure. Observational studies are scarce and describe controversial findings, which might be addressed by discrepancies in the selection of study populations (variable sample size, different criteria for subject selection, presence or absence of adequate control group), technical pitfalls (different patterns of $\mathrm{Cd}$ exposure, multiple exposure to several pollutants, interactions between Cd and different metals, lack of information for factors affecting $\mathrm{Cd}$ absorption and tissue distribution, or affecting reproduction per se) or statistical drawbacks (lack of adjustment for confounding variables). Moreover, the available occupational studies are cross-sectional, and do not appraise latency of effects, duration and fluctuation of former Cd exposure, and changes of the endpoints of interest over time, by making it demanding to set a quantitative dose-response relationship, or exposure thresholds. Lastly, either in environmental or occupational studies, the inappropriate choice of the biological fluid used for the quantification of Cd exposure could also account for inconsistencies in the literature. Indeed, according to several studies, no correlation exists among whole blood Cd (bCd), bpCd, or serum $\mathrm{Cd}(\mathrm{sCd})$, and seminal plasma $\mathrm{Cd}(\mathrm{spCd})$, suggesting that local $\mathrm{Cd}$ concentration in the reproductive system is not mirrored by circulating $\mathrm{Cd}$ concentration; moreover, just one study measured urine $\mathrm{Cd}(\mathrm{uCd})$, therefore, the biological relevance of this parameter has not been validated, as concerns its significance for the assessment of local $\mathrm{Cd}$ concentration in the reproductive system. As a consequence of these evidences, spCd concentration is 
Table 1

Summary at a glance of epidemiological observational studies on the effects of cadmium exposure on semen quality in humans.

\begin{tabular}{|c|c|c|c|c|c|c|c|c|c|c|c|}
\hline & \multirow[b]{2}{*}{$\begin{array}{l}\text { No subjects } \\
\text { Type of exposure }\end{array}$} & \multirow[b]{2}{*}{$\begin{array}{l}\text { No subjects/ } \\
\text { group }\end{array}$} & \multirow[b]{2}{*}{ Age } & \multirow[b]{2}{*}{ Seminal profile } & \multirow[b]{2}{*}{$\begin{array}{l}\text { Cadmium dosage } \\
\text { (n samples) }\end{array}$} & \multicolumn{6}{|c|}{ Seminal Parameters } \\
\hline & & & & & & Semen volume & $\begin{array}{l}\text { Sperm } \\
\text { total count }\end{array}$ & $\begin{array}{l}\begin{array}{l}\text { Sperm } \\
\text { concentration }\end{array}\end{array}$ & $\begin{array}{l}\begin{array}{l}\text { Sperm } \\
\text { vitality }\end{array} \\
\text { val }\end{array}$ & $\begin{array}{l}\text { Sperm } \\
\text { motility }\end{array}$ & $\begin{array}{l}\text { Sperm } \\
\text { morphology }\end{array}$ \\
\hline Akinloye et al. [17] & 100 Env. & $\begin{array}{l}\text { group 1: } \\
6 \text { O IP } \\
\text { group 2: } \\
40 \text { Fertile }\end{array}$ & R 20-45 & $\begin{array}{l}\text { group 1: } \\
40 \mathrm{O} ; 2 \mathrm{Az} \\
\text { group 2: } \\
40 \mathrm{~N}\end{array}$ & $\begin{array}{l}S(n=100) \\
S P(n=100)\end{array}$ & $S=S P=$ & $S \downarrow S P=$ & Na & $S \downarrow S P=$ & $S \downarrow S P=$ & $S \downarrow S P=$ \\
\hline Benoff et al. [27] & 190 Env. & $\begin{array}{l}\text { group 1: } \\
140 \text { IP } \\
\text { group 2: } \\
15 \text { SD } \\
\text { group 3: } \\
35 \text { UNS }\end{array}$ & $\mathrm{NA}$ & $\begin{array}{l}\text { group 1: } \\
34 \mathrm{~N} ; 84 \mathrm{O} / \mathrm{A} / \mathrm{T} \\
\text { and combined; } \\
22 \mathrm{NA} \\
\text { group 2: } \\
\mathrm{N} \\
\text { group 3: } \\
\text { majority N }\end{array}$ & $\begin{array}{l}\text { BP }(n=140) \\
S P(n=181)\end{array}$ & $\mathrm{Na}$ & $\mathrm{Na}$ & $\begin{array}{l}\text { group 1: } \\
\text { BP = SP } \downarrow \\
\text { group 2: } \\
\text { BP NA SP = } \\
\text { group 3: } \\
\text { BP NA SP = }\end{array}$ & $\mathrm{Na}$ & $\begin{array}{l}\text { group 1: } \\
\text { B }=S P \downarrow \\
\text { group 2: } \\
\text { B NA SP = } \\
\text { group 3: } \\
\text { BP NA SP }=\end{array}$ & $\begin{array}{l}\text { group 1: } \\
\text { BP = SP = } \\
\text { group 2: } \\
\text { BP NA SP = } \\
\text { group 3: } \\
\text { BP NA SP = }\end{array}$ \\
\hline Pant et al. [28] & $119 \mathrm{Env}$. & $\begin{array}{l}\text { group 1: } \\
46 \text { Fertile } \\
\text { group 2: } \\
73 \text { Infertile }\end{array}$ & $\begin{array}{l}\text { R R20-43 } \\
\text { group 1: } \\
\text { M 32 } \\
\text { group 2: } \\
\text { M 33 }\end{array}$ & $\mathrm{NA}$ & $S P(n=119)$ & Na & Na & SP $\downarrow$ & $\mathrm{Na}$ & $\mathrm{SP} \downarrow$ & $\mathrm{Na}$ \\
\hline Mendiola et al. [22] & 61 Env. & $61 \mathrm{IP}$ & M 33 & $\begin{array}{l}\text { group 1: } \\
30 \text { OAT } \\
\text { group 2: } \\
31 \mathrm{~N}\end{array}$ & $\begin{array}{l}\mathrm{B}(\mathrm{n}=59) \\
\mathrm{BP}(\mathrm{n}=61) \\
\mathrm{SP}(\mathrm{n}=61)\end{array}$ & $\mathrm{Na}$ & $\mathrm{Na}$ & $B=B P=S P=$ & $\mathrm{Na}$ & $\mathrm{B}=\mathrm{BP}=\mathrm{SP} \downarrow$ & $B=B P=S P=$ \\
\hline Chia et al. [29] & 35 Env. & $35 \mathrm{IP}$ & M 38 & UNS & $B P(n=35)$ & $\mathrm{BP} \downarrow$ & $\mathrm{Na}$ & $\mathrm{BP}=$ & $\mathrm{Na}$ & $B P=$ & $\mathrm{BP} \downarrow$ \\
\hline Guzikowski et al. [31] & 34 Env. & $34 \mathrm{IP}$ & $\begin{array}{l}\text { R 26-42; } \\
\text { M 29 }\end{array}$ & $\begin{array}{l}\text { group 1: } \\
23 / \mathrm{A} / \mathrm{T} \text { and combined } \\
\text { group 2: } \\
11 \mathrm{~N}\end{array}$ & $S P(n=34)$ & Na & SP $\downarrow$ & Na & $\mathrm{Na}$ & $S P \downarrow$ & $S P \downarrow$ \\
\hline Telisman et al. [32] & 149 Env. & $\mathrm{NA}$ & $\begin{array}{l}\text { R 20-43; } \\
\text { m 30.5; } \\
\text { M 30.5 }\end{array}$ & $\mathrm{NA}$ & $\begin{array}{l}\text { BP (n=149) } \\
\text { SP (n=118) }\end{array}$ & $\mathrm{BP}=\mathrm{SP}=$ & $B P=S P=$ & $\mathrm{BP}=\mathrm{SP}=$ & $\mathrm{BP}=\mathrm{SP}=$ & $\mathrm{BP}=\mathrm{SP}=$ & $\mathrm{BP} \downarrow \mathrm{SP}=$ \\
\hline Xuet al. [30] & 221 Env. & $221 \mathrm{IP}$ & $\begin{array}{l}\text { R 24-54; } \\
\text { M 35 }\end{array}$ & NA & $\begin{array}{l}\text { BP (n=191) } \\
\operatorname{SP}(n=74)\end{array}$ & $B P=S P \downarrow$ & NA & $\mathrm{BP} \downarrow \mathrm{SP}=$ & $B P=S P=$ & $B P=S P=$ & $\mathrm{BP}=\mathrm{SP} \downarrow$ \\
\hline Xuet al. [34] & 56 Env. & $\mathrm{NA}$ & $\begin{array}{l}\text { R 26-45; } \\
\text { M 35 }\end{array}$ & $\mathrm{NA}$ & $S P(n=56)$ & $S P=$ & $\mathrm{SP} \downarrow$ & $\operatorname{SP} \downarrow$ & $S P=$ & $S P=$ & $S P=$ \\
\hline Meeker et al. [37] & $219 \mathrm{Env}$. & $219 \mathrm{IP}$ & $\begin{array}{l}\text { R 18-55; } \\
\text { m 34 }\end{array}$ & $\begin{array}{l}\text { group 1: } \\
73 \mathrm{~N} \\
\text { group 2: } \\
146 \mathrm{O} / \mathrm{A} / \mathrm{T} \text { and combined }\end{array}$ & $B P(n=219)$ & $B P=$ & $B P=$ & $B P=$ & $\mathrm{Na}$ & $B P=$ & $B P=$ \\
\hline Jurasovic et al. [38] & 123 Env. & IP & $\begin{array}{l}\text { R 19-48; } \\
\text { m 31 }\end{array}$ & $\mathrm{NA}$ & $B P(n=123)$ & Na & $\mathrm{Na}$ & $B P=$ & $\mathrm{BP}=$ & $B P=$ & $B P=$ \\
\hline Keck et al. [39] & $\begin{array}{l}174 \text { Env. } \\
2 \text { Occ. }\end{array}$ & $\begin{array}{l}\text { group 1: } \\
12 \text { Fertile } \\
\text { group 2: } \\
44 \text { Infertile Idiopathic } \\
\text { group 3: } \\
118 \text { Infertile } \\
\text { group 4: } \\
2 \text { IP occ. }\end{array}$ & $\begin{array}{l}\text { group 1: } \\
\text { NA } \\
\text { group 2: } \\
\text { M 35 } \\
\text { group 3: } \\
\text { M 26 } \\
\text { group 4: } \\
\text { 34 and 35 }\end{array}$ & $\begin{array}{l}\text { group 1: } \\
N \\
\text { group 2: } \\
N \\
\text { group 3: } \\
\text { UNS } \\
\text { group 4: } \\
\text { OT and OAT }\end{array}$ & $S P(n=176)$ & $S P=$ & $\mathrm{Na}$ & $\mathrm{SP}=$ & $\mathrm{Na}$ & $S P=$ & $S P=$ \\
\hline Hovatta et al. [43] & $\begin{array}{l}27 \text { Occ. } \\
45 \text { Env. }\end{array}$ & $\begin{array}{l}\text { group 1: } \\
\text { 27 factory employees } \\
\text { group 2: } \\
45 \mathrm{SD}\end{array}$ & $\begin{array}{l}\text { group 1: } \\
\text { R 27-46; M } 34 \\
\text { group 2: } \\
\text { R 20-45; M } 28\end{array}$ & $\mathrm{NA}$ & $\begin{array}{l}\mathrm{SP}(\mathrm{n}=72) \\
\operatorname{SPZ}(\mathrm{n}=72)\end{array}$ & Na & Na & $S P=S P Z=$ & Na & $\mathrm{SP}=\mathrm{SPZ}=$ & $S P=S P Z=$ \\
\hline
\end{tabular}

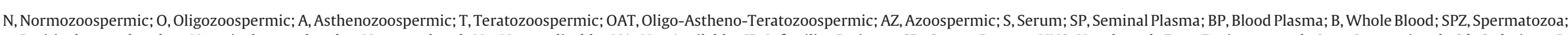

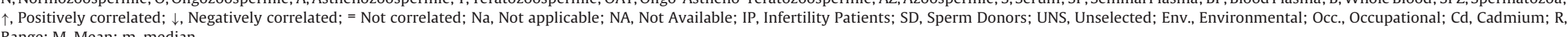
Range; M, Mean; m, median. 
Table 2

Summary at a glance of epidemiological observational studies on the effects of cadmium exposure on reproductive endocrine function in humans

\begin{tabular}{|c|c|c|c|c|c|c|c|c|c|c|}
\hline & \multirow[b]{2}{*}{$\begin{array}{l}\mathbf{N}^{\circ} \text { subjects } \\
\text { Type of exposure }\end{array}$} & \multirow[b]{2}{*}{$\begin{array}{l}\mathrm{N}^{\circ} \text { subjects/ } \\
\text { group }\end{array}$} & \multirow[b]{2}{*}{ Age } & \multirow[b]{2}{*}{ Seminal profile } & \multirow[b]{2}{*}{$\begin{array}{l}\text { Cadmium dosage } \\
\text { ( } \mathrm{n}^{\circ} \text { samples) }\end{array}$} & \multicolumn{5}{|c|}{ Reproductive Endocrine Function (serum hormone) } \\
\hline & & & & & & Testosterone & Estradiol & FSH & LH & Prolactin \\
\hline Akinloye et al. [17] & 100 Env. & $\begin{array}{l}\text { group 1: } \\
60 \text { IP } \\
\text { group 2: } \\
40 \text { Fertile }\end{array}$ & R 20-45 & $\begin{array}{l}\text { group 1: } \\
40 \text { O; } 20 \mathrm{AZ} \\
\text { group 2: } \\
40 \mathrm{~N}\end{array}$ & $\begin{array}{l}S(n=100) \\
S P(n=100)\end{array}$ & $S=S P=$ & $\mathrm{Na}$ & $S=S P=$ & $S=S P=$ & $S=S P=$ \\
\hline Benoff et al. [27] & 190 Env. & $\begin{array}{l}\text { group 1: } \\
140 \text { IP } \\
\text { group 2: } \\
15 \text { SD } \\
\text { group 3: } \\
35 \text { UNS }\end{array}$ & $\mathrm{NA}$ & $\begin{array}{l}\text { group 1: } \\
34 \mathrm{~N} ; 84 \mathrm{O} / \mathrm{A} / \mathrm{T} \\
\text { and combined; } \\
22 \mathrm{NA} \\
\text { group 2: } \\
\mathrm{N} \\
\text { group 3: } \\
\text { majority N }\end{array}$ & $\begin{array}{l}\text { BP (n=140) } \\
\text { SP (n=181) }\end{array}$ & $\begin{array}{l}\text { group 1: } \\
\text { BP = P = } \\
\text { group 2: } \\
\text { BP NA SP NA } \\
\text { group 3: } \\
\text { BP NA SP NA }\end{array}$ & $\mathrm{Na}$ & $\begin{array}{l}\text { group 1: } \\
\text { BP = SP = } \\
\text { group 2: } \\
\text { BP NA SP NA } \\
\text { group 3: } \\
\text { BP NA SP NA }\end{array}$ & $\begin{array}{l}\text { group 1: } \\
\text { BP = SP = } \\
\text { group 2: } \\
\text { BP NA SP NA } \\
\text { group 3: } \\
\text { BP NA SP NA }\end{array}$ & $\mathrm{Na}$ \\
\hline Mendiola et al. [22] & 61 Env. & $61 \mathrm{IP}$ & M33 & $\begin{array}{l}\text { group 1: } \\
30 \text { OAT } \\
\text { group 2: } \\
31 \mathrm{~N}\end{array}$ & $\begin{array}{l}B(n=59) \\
B P(n=61) \\
S P(n=61)\end{array}$ & $\mathrm{B}=\mathrm{BP}=\mathrm{SP}=$ & $\mathrm{Na}$ & $B=B P=S P=$ & $B=B P=S P=$ & $\mathrm{Na}$ \\
\hline Jurasovic et al. [38] & 123 Env. & IP & $\begin{array}{l}\text { R 19-48; } \\
\text { m 31 }\end{array}$ & NA & $B P(n=123)$ & $\mathrm{BP} \uparrow$ & $\mathrm{BP} \uparrow$ & $\mathrm{BP} \uparrow$ & $B P=$ & $B P=$ \\
\hline Telisman et al. [32] & 149 Env. & $\mathrm{NA}$ & $\begin{array}{l}\text { R 20-43; } \\
\text { m 30.5; } \\
\text { M 30.5 }\end{array}$ & NA & $\begin{array}{l}\text { BP (n=149) } \\
\text { SP (n=118) }\end{array}$ & $\mathrm{BP} \uparrow \mathrm{SPNa}$ & $B P=S P N a$ & $\mathrm{BP}=\mathrm{SPNa}$ & $\mathrm{BP} \uparrow \mathrm{SPNa}$ & BP $\downarrow$ SP Na \\
\hline Meeker et al. [41] & 219 Env. & $219 \mathrm{IP}$ & $\begin{array}{l}\text { R 18-55; } \\
\text { m 34 }\end{array}$ & $\begin{array}{l}\text { group 1: } \\
73 \mathrm{~N} \\
\text { group 2: } \\
\text { 146 O/A/T and combined }\end{array}$ & $B P(n=219)$ & $B P=$ & $\mathrm{Na}$ & $\mathrm{BP}=$ & $\mathrm{BP}=$ & $\mathrm{Na}$ \\
\hline Zeng et al. [42] & 263 Env. & $\begin{array}{l}\text { group 1: } \\
93 \text { from control } \\
\text { area } \\
\text { group 2: } \\
71 \text { from medium } \\
\text { Cd polluted area } \\
\text { group 3: } \\
99 \text { from heavily } \\
\text { Cd polluted area }\end{array}$ & $\geq 35$ & $\mathrm{NA}$ & $\begin{array}{l}\text { BP }(n=263) \\
U(n=263)\end{array}$ & $B P=U=$ & $\mathrm{Na}$ & $B P=U=$ & $B P=U=$ & $\mathrm{Na}$ \\
\hline Zeng et al. [44] & $\begin{array}{l}80 \text { Env. } \\
86 \text { Occ. }\end{array}$ & $\begin{array}{l}\text { group 1: } \\
8 \text { E Env. } \\
\text { group 2: } \\
38 \text { slight to } \\
\text { moderate Occ. } \\
\text { group 3: } \\
48 \text { heavy Occ. }\end{array}$ & R 21-78 & $\mathrm{NA}$ & $U(n=166)$ & $U \uparrow^{a}$ & $\mathrm{Na}$ & $u=$ & $U \uparrow^{\mathrm{b}}$ & $\mathrm{Na}$ \\
\hline
\end{tabular}

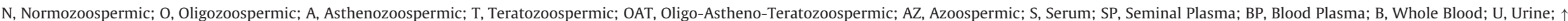

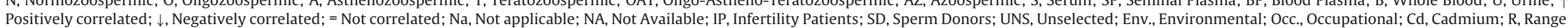
$M$, Mean; m, median.

${ }^{b}$ Positively correlated only for urinary Cd concentrations of $20 \mu \mathrm{g} / \mathrm{g}$ creatinine or higher. 
likely the best parameter to be considered in studies on Cd effect on reproduction $[22,23]$. The current review summarizes findings from observational studies considering the influence of environmental and occupational Cd exposure on reproductive function in terms of semen quality (Table 1) and endocrine function (Table 2).

\subsection{Environmental exposure}

The observational studies on the effects of environmental $\mathrm{Cd}$ exposure on reproductive function in humans focus on semen quality and on endocrine function.

\subsubsection{Effect of cadmium exposure on semen quality}

The studies focusing on the correlation between exposure to $\mathrm{Cd}$ at environmental concentrations and semen quality are controversial; several studies found a significant negative correlation between $\mathrm{Cd}$ concentration and semen parameters, whereas some studies failed to demonstrate a clear correlation between Cd exposure and semen quality.

Several studies in environmentally exposed subjects pointed out that, even at environmental concentration, $\mathrm{Cd}$ may exert a detrimental effect on semen quality. Tobacco smoking significantly increases bpCd and spCd concentration [24,25], and was shown to adversely affect semen quality, including sperm total count, concentration, motility and morphology [26], thus suggesting that Cd might partially contribute to the reprotoxicity of tobacco smoking. A Nigerian study compared sCd and spCd concentration in 60 infertile men (40 with oligozoospermia and 20 with azoospermia) attending fertility clinics, and 40 age-matched men with normozoospermia and proven fertility [17]. The results of the study showed that spCd concentration was significantly higher than sCd concentration in both infertile and fertile men, and that sCd and spCd concentration was significantly higher in infertile azoospermic, compared to infertile oligozoospermic and fertile normozoospermic men [17]. Moreover, a significant negative correlation was found between $\mathrm{sCd}$, but not spCd, concentration, and semen parameters, such as sperm concentration, motility, morphology and vitality, but not semen volume [17]. Conversely, in a US study, a significant negative correlation was reported between spCd concentration and sperm concentration, as well as sperm motility, in male partners of infertile couples; this correlation was not found in sperm donors for artificial insemination and in general population volunteers [27]. These observations were confirmed by an Indian study on healthy fertile and infertile men attending a fertility centre, reporting a negative correlation between spCd concentration and semen parameters, including sperm concentration and motility [28]. A Spanish study performed in male partners of couples attending three fertility centers, enrolled 61 patients, which were classified, based on semen quality, in 30 case (men with oligo-astheno-teratozoospermia) and 31 control (men with normozoospermia) subjects [22]. In this study, a significant negative correlation was found between spCd concentration and sperm motility, after adjustment for age, body mass index, and number of cigarettes per day, although no correlation was detected between spCd, bCd, or bpCd concentration and sperm concentration or morphology [22]. A Singapore study on 35 men, including subjects with normal or idiopathic impairment of semen quality (the overall group semen profile displayed oligozoospermia and teratozoospermia, with borderline asthenozoospermia), attending an andrology clinic, found that asthenozoospermic men had significantly higher bpCd concentration compared to men with normal sperm motility, and demonstrated a significant positive correlation between bpCd concentration and sperm midpiece defects or immature forms, and a negative correlation between bpCd concentration and semen volume [29]. A different Singapore study on 221 men undergoing initial screening for infertility, correlated
bpCd and spCd concentration to semen parameters, by reporting a significant negative correlation between bpCd concentration and sperm concentration, and between spCd concentration and semen volume, whereas a weak negative correlation was found between spCd concentration and the percentage of spermatozoa with normal morphology [30]. A Poland study on 34 men selected from primary infertile couples living in a rural area, reported a significant negative correlation between spCd concentration and sperm total count, motility and morphology [31]. A Croatian study on 149 healthy male industrial workers not exposed to Cd, consistently showed that bpCd concentration was negatively correlated to the percentage of spermatozoa with normal morphology [32]. A Slovak study on 47 subjects referring to a fertility centre, and focusing on sperm morphology, showed that spCd concentration had a mild negative correlation with the percentage of spermatozoa with normal morphology, in particular, a positive corretation with the number of spermatozoa with large heads was reported [33]. Furthermore, a Chinese study on 56 non-smoker men reported that spCd concentration was negatively correlated to sperm total count and concentration [34]; in this study, the sperm DNA levels of 8-hydroxy-2'-deoxyguanosine (8-OHdG), a critical biomarker of oxidative stress, were negatively correlated to sperm total count, concentration and vitality, but positively correlated to spCd concentration, suggesting that the oxidative stress and the consequent DNA damage might be a mechanism of Cd reprotoxicity [34]. The role of $\mathrm{Cd}$ in sperm oxidative damage was also confirmed in a Turkish study on 95 subjects, including 50 infertile and 45 fertile men [35]. Lastly, a US study on 64 apparently healthy men recruited at a fertility centre, reported a negative correlation between $\mathrm{spCd}$ concentration and the percentage of vital sperm [36] .

In disagreement with the above-mentioned studies, a group of studies failed to find a clear correlation between sCd, bpCd, or spCd concentration, and semen quality. In particular, a US study on 219 patients recruited at fertility clinics, including fertile and infertile men, reported absence of correlation between $\mathrm{Cd}$ exposure and semen quality [37]. A Croatian study in 123 men attending fertility clinics did not report any correlation between Cd exposure and semen quality, after adjustment for potential confounders [38]. A German study did not describe any correlation between spCd concentration and semen quality in 12 men with proven fertility, 44 patients with normozoospermia and idiopathic infertility, 118 infertile patients unselected for semen quality, and 2 occupationally exposed workers attending a fertility centre, although information concerning smoking habits was not available in a group of patients [39]. In a Finnish study on 64 subjects including sperm donors and fertile men, which were then stratified for tobacco smoking, sCd and spCd concentration was higher in smokers than in non-smokers, although no significant difference was observed in semen quality and fertility outcome between the two groups of subjects [40].

\subsubsection{Effect of cadmium exposure on endocrine function}

The studies focusing on the correlation between exposure to $\mathrm{Cd}$ at environmental concentrations and the endocrine function are controversial. In a Croatian study on 123 men attending fertility clinics, bpCd concentration was correlated to serum hormone concentrations, after adjustment for age, tobacco smoking and alcohol consumption [38]; bpCd concentration (median $2.94 \mu \mathrm{g} / \mathrm{L}$ in smokers, and $0.59 \mu \mathrm{g} / \mathrm{L}$ in non smokers) was negatively correlated to testis size, and positively correlated to follicle stimulating hormone (FSH), testosterone ( $\mathrm{T})$, and estradiol ( $\left.\mathrm{E}_{2}\right)$ serum concentration [38] . A different Croatian study on healthy male industrial workers not exposed to $\mathrm{Cd}$ found a significant positive correlation between bpCd concentration and serum luteinizing hormone (LH) and T concentration, and a negative correlation between bpCd concentration and serum prolactin concentration [32]. A US study on men 
attending two fertility clinics reported that bpCd concentration was positively correlated to serum inhibin $\mathrm{B}$ (INH-B) concentration, in a model adjusted for tobacco smoking, age, BMI, and potential interaction with different metals [41]. A Nigerian study on 60 men with oligozoospermia or azoospermia and infertility, and 40 agematched normozoospermic men with proven fertility, showed that spCd concentration was positively correlated to seminal plasma FSH concentration [17]. Conversely, in a Spanish study on 30 case (oligo-astheno-teratozoospermia) and 31 control (normozoospermia) subjects from couples attending three fertility centers, no significant correlation was reported between serum FSH, LH and T concentration and bCd, bpCd and spCd concentration [22]. Similar results were reported in a US study on 140 male partners of infertile couples, including subjects with normozoospermia, oligozoospermia, azoospermia and fertile subjects [27]. Lastly, in a Chinese study on 263 male volunteers from a control area and two Cd-polluted areas, no significant correlation was found between uCd concentration and serum FSH, LH and T concentration, after adjustment for potential confounders [42].

\subsection{Occupational exposure}

The observational studies on the effects of occupational Cd exposure on reproductive function in humans focus on semen quality and endocrine function.

\subsubsection{Effect of cadmium exposure on semen quality and endocrine function}

The studies evaluating the correlation between occupational exposure to $\mathrm{Cd}$ and semen quality, and endocrine function are scant. A Finnish study measured Cd burden in seminal plasma and spermatozoa of 27 occupationally exposed subjects working in a refinery and a polyolefin factory, and 45 environmentally exposed sperm donor candidates [43]; surprisingly, significantly higher concentrations of $\mathrm{Cd}$ were found in both seminal plasma and spermatozoa of sperm donor candidates, probably as a consequence of the occupational protection policy, and the countryside domicile of most of the employees of the industries [43]. Moreover, the overall concentration of Cd measured in the seminal plasma and spermatozoa was very low, reflecting low levels of exposure in both study populations, and no correlation was reported between Cd concentration and sperm concentration, motility or morphology [43]. A Chinese study on smelter workers exposed to Cd and control subjects, showed that creatinine-adjusted uCd concentration positively correlated to serum LH and T, but not FSH concentration, after adjustment for potential confounders, such as age, smoking habits, and alcohol consumption [44].

\subsection{Concluding remarks on observational studies in humans}

The evidences derived from the observational studies in humans suggest that both environmental and occupational patterns of $\mathrm{Cd}$ exposure have a detrimental effect on semen quality, and can alter endocrine function. Nevertheless, some studies failed to identify differences between Cd exposed and non-exposed subjects, in both environmental and occupational exposure settings, probably due to small-sized study populations, and lack of control for potential confounding variables.

\section{Cadmium and male reproduction: experimental studies in humans}

The experimental studies investigating the effect of $\mathrm{Cd}$ exposure on male reproduction in humans are restricted to in vitro studies on spermatozoa, which are obtained through ejaculation. Two are the main studies evaluating the effect of $\mathrm{Cd}$ treatment on spermatozoa. In the first study, semen samples with normal semen parameters collected from a cohort of 60 fertile men and 150 men with idiopathic infertility, were subjected to Cd treatment [45]. Cd was found to significantly decrease sperm motility, in a time-dependent fashion; moreover, a significant dose-dependent and time-dependent decrease in sperm vitality was observed during Cd treatment [45]. In the second study Cd was shown to alter the activity of key enzymes involved in spermatozoa metabolism; in particular, treatment with $\mathrm{CdCl} 2$ inhibited the activity of glycogen phosphorylase, glucose6-phosphatase, fructose-1,6-diphosphatase, glucose-6-phosphate isomerase, amylase, $\mathrm{Mg}^{2+}$ - dependent ATPase, and lactic and succinic acid dehydrogenases [46]. Therefore, the experimental in vitro studies on human spermatozoa suggest that Cd might affect semen quality in humans, and that the impairment of semen quality may be mediated by detrimental effects on spermatozoa metabolism.

\section{Cadmium and male reproduction: experimental studies in animals}

The experimental studies investigating the effect of $\mathrm{Cd}$ exposure on male reproduction in animals include in vivo studies on animal models of $\mathrm{Cd}$ intoxication, which provide direct evidences of the toxic effects of $\mathrm{Cd}$ on several aspects of the reproductive function, including development of reproductive system, endocrine function, spermatogenesis and semen quality, and, consequently, fertility; the main findings of these studies are briefly summarized in Table 3.

The studies in experimental animal models of $\mathrm{Cd}$ exposure demonstrated that $\mathrm{Cd}$ is gonadotoxic and spermiotoxic, when administered as either a single high dose, or chronic low doses, and that its harmful effect on reproduction can be long-lasting and irreversible, if animals are treated during fetal development, early life, or before the pubertal period, most probably due to the severe damage induced to proliferating and differentiating Sertoli cells, which exert a crucial role in the development of a functional testis, and in spermatogenesis [47]. Pregnant mice injected intraperitoneally (IP), daily, with $0.5 \mathrm{mg} / \mathrm{kg}$ body weight $\mathrm{CdCl} 2$, during the late pregnancy period (gestational day 13-17) delivered male fetuses with reduced body and testis weight, and showing defective steroidogenesis and decreased serum T concentrations [48]. Noteworthy, at adulthood, the male offspring maintained the decreased concentration of $\mathrm{T}$, both in the general circulation and within the testis, and displayed reduction of fertility, as measured by the number of live birth per litter, in breeding experiments with untreated females [48]. Mouse male embryos exposed to $\mathrm{CdCl} 2$ during early organogenesis showed smaller genital ridges and fewer primordial germ cells (day 13.5); moreover, these embryos developed smaller testis with a reduced number of differentiating germ cells, due to an extensive degeneration process (day 16.5) [49]. Lastly, the fertility of the prenatally-exposed male offspring was impaired, as the result of a defective development of the gonads, depletion of germ cells, and impairment of spermatozoa maturation, as demonstrated by a lower in vitro fertilization rate [49]. A 0.4 , or $0.8 \mathrm{mg} / \mathrm{kg}$ body weight dose of $\mathrm{CdCl} 2$ solution administered IP to adult rats significantly reduced $(0.4 \mathrm{mg} / \mathrm{kg}$ body weight), or completely abolished $(0.8 \mathrm{mg} / \mathrm{kg}$ body weight $)$ sperm motility, and drastically affected daily spermatozoa production only at the highest dose ( $0.8 \mathrm{mg} / \mathrm{kg}$ body weight) [50]. A $1 \mathrm{mg} / \mathrm{kg}$ body weight dose of $\mathrm{CdCl} 2$ solution administered IP to adult rats resulted in a time-dependent failure of the last step of spermatogenesis (spermiation in the seminiferous epithelium), without pathological changes in the surrounding vascular endothelium [51]. A $5 \mathrm{mg} / \mathrm{kg}$ body weight $\mathrm{CdCl} 2$ administered to rats by oral gavage, every other day for 30 days, caused a significant decrease in sperm concentration, sperm motility, and testis and epididymis weight, as well as an increase in the percentage of dead spermatozoa and spermatozoa with abnormal morphology [52]. The effects of 1 or $5 \mathrm{mg} / \mathrm{kg}$ body weight doses of 
Table 3

Summary at a glance of experimental in vivo studies on cadmium reproductive toxicity in animal models.

\begin{tabular}{|c|c|c|c|c|}
\hline & Experimental Model & Compound/Dose/Route & Treatment schedule & Main findings \\
\hline Jiet al. [48] & Pregnant mice & $\mathrm{CdCl} 2 / 0.5 \mathrm{mg} / \mathrm{Kg}$ BW/P & Injected daily from $\mathrm{gd} 13$ to $\mathrm{gd} 17$ & $\begin{array}{l}\text { - Male embryos (gd 18) of reduced weight and reduced testis weight, showing defective } \\
\text { steroidogenessis and reduced serum testosterone } \\
\text { Male offspring (PND } 70 \text { ) showed defective steroidogenesis and reduced testosterone in serum } \\
\text { and within the testis } \\
\text { - Impaired fertility of male offspring }\end{array}$ \\
\hline Tam and Liu [49] & Pregnant mice & $\mathrm{CdCl} 2 / 5-6 \mathrm{mg} / \mathrm{kg} \mathrm{BW} / \mathrm{IP}$ & Injected once at 7.5 or $8.5 \mathrm{dpc}$ & $\begin{array}{l}\text { Male embryos (gd 13.5) showed smaller genital ridges with fewer primordial germ cells } \\
\text { - Male embryos (gd 16.5) showed smaller testes with reduced number of spermatogonia } \\
\text { Impaired fertility of male offspring }\end{array}$ \\
\hline Xu et al. [50] & Rats & $\mathrm{CdCl} / 0.2,0.4,0.8 \mathrm{mg} / \mathrm{Kg} \mathrm{BW} / \mathrm{PP}$ & Injected daily for 7 days & $\begin{array}{l}\text { - Decreased or completely abolished sperm motility (Dose-dependent) } \\
\text { - Reduced sperm total count and daily sperm production ( }(0.8 \mathrm{mg} / \mathrm{kg} \mathrm{BW})\end{array}$ \\
\hline Hew et al. [51] & Rats & $\mathrm{CdCl} 2 / 0.5$ or $1 \mathrm{mg} / \mathrm{kg} \mathrm{BW} / \mathrm{IP}$ & $\begin{array}{l}\text { Injected once and sacrificed } \\
\text { after } 4,24,48 \text { and } 72 \text { hours }\end{array}$ & - Failure of the last step of spermatogenesis (spermiation) $(1 \mathrm{mg} / \mathrm{Kg} \mathrm{BW})$ \\
\hline El-Demerdash et al. [52] & Rats & $\mathrm{CdCl} 2 / 5 \mathrm{mg} / \mathrm{Kg} \mathrm{BW} / \mathrm{OG}$ & $\begin{array}{l}\text { Administered every other day, } \\
\text { for } 30 \text { days ( } 15 \text { times) }\end{array}$ & $\begin{array}{l}\text { - } \text { Decreased sperm concentration } \\
\text { - } \text { Increaseased abnorm motility sperm morphology } \\
\text { - Increased number of dead spermatozoa } \\
\text {. }\end{array}$ \\
\hline Saksena and Lau [53] & Rats & $\mathrm{CdCl} 2 / 1$ or $5 \mathrm{mg} / \mathrm{Kg} \mathrm{BW} / \mathrm{SC}$ & $\begin{array}{l}\text { Injected once } \\
\text { Follow up of } 120 \text { days }\end{array}$ & $\begin{array}{l}\text { - Reduced weight of testis }(5 \mathrm{mg} / \mathrm{Kg} \mathrm{BW}) \text { and epididymis, seminal vesicles and prostate }(1 \text { and } 5 \\
\text { mg/Kg BW) } \\
\text { - Impaired steroidogenesis and fertility } \\
\text { - Infertility partially reverted within } 120 \text { days }(1 \mathrm{mg} / \mathrm{Kg} \mathrm{BW}) \text { or persistent }(5 \mathrm{mg} / \mathrm{Kg} \mathrm{BW})\end{array}$ \\
\hline Laskey et al. [54] & Rats & CdCl2/1.6 to $152 \mu \mathrm{mol} / \mathrm{Kg} \mathrm{BW} / \mathrm{SC}$ & Injected once and sacrificed after 14 days & $\begin{array}{l}\text { - Decreased sperm concentration }(7.4 \mu \mathrm{MM} / \mathrm{Kg} \mathrm{BW}) \\
\text { Reduced hCG-stimulated serum testosterone }(1.6 \text { and } 7.4 \mu \mathrm{MM} / \mathrm{Kg} \mathrm{BW}) \\
\text { Reduced weight of testis, epididymis and seminal vesicles, abolished spermatogenesis, abolished } \\
\text { hG-stimulated serum testosterone }(16 \text { and } 33 \mu \mathrm{MM} / \mathrm{Kg} \mathrm{BW})\end{array}$ \\
\hline Lafuente et al. [55] & Rats & CdCl2/25 mg/L/DW & Administered daily for 1 month & - Affected daily pattern of gonadotropins and testosterone \\
\hline Benoff et al. [56] & Rats & $\begin{array}{l}\text { CdCI2/5, } 50 \text { or } 100 \mathrm{mg} / \mathrm{L} / \mathrm{DW} \\
\text { Realistic dose received: } 1.6,6.4,12.6 \mathrm{mg} / \mathrm{Kg} \text { BW per day }\end{array}$ & Administered daily for 1,4 or 8 weeks & - Decreased sperm motility (Dose-dependent and time-dependent) \\
\hline Saygi et al. [57] & Rats & $\mathrm{Cd} / 10 \mathrm{mg} / \mathrm{L} / \mathrm{DW}$ & Administered daily for 28,40 and 52 weeks & $\begin{array}{l}\text { Pathological testis alterations } \\
\text { Impaired fertility }\end{array}$ \\
\hline Monsefi et al. [58] & Mice & $\mathrm{CdCl} / 2 / 23$ and $50 \mathrm{mg} / \mathrm{Kg} \mathrm{BW} / \mathrm{OG}$ & Administered daily for 45 days & $\begin{array}{l}\text { In the } 50 \mathrm{mg} / \mathrm{Kg} \mathrm{BW} \text { treatment: } \\
\text { Decreased sperm total count } \\
\text { - Decreased sperm motility } \\
\text { Decreased spermatozoa nuclear maturity } \\
\text { - Reduced weight of testis and seminal vesicles, and reduced serum testosterone }\end{array}$ \\
\hline
\end{tabular}

BW, Body Weight; gd, gestational day; PND, Post Natal Day; dpc, days post coitum; IP, Intraperitoneal; OG, Oral Gavage; SC, Subcutaneous; DW, Drinking Water; NA, Not Available. 
$\mathrm{CdCl} 2$ administered to rats as a single subcutaneous (SC) injection were also determined in experiments with a follow up of 120 days; circulating $\mathrm{T}$ and fertility were affected at the lower dose of $\mathrm{CdCl} 2$, whereas the higher dose of $\mathrm{CdCl} 2$ affected $\mathrm{T}$ and androstenedione, as well as fertility [53]. However, within 120 days from both the 1 and $5 \mathrm{mg} / \mathrm{kg}$ body weight dose treatment, the effects of $\mathrm{CdCl} 2$ on circulating hormones were reversed, although circulating concentrations remained lower than normal [53]; conversely, whereas animals trated with $1 \mathrm{mg} / \mathrm{kg}$ body weight partially recovered fertility, after the treatment with the $5 \mathrm{mg} / \mathrm{kg}$ body weight dose, animals remained sterile [53]. The exposure of adult rats to low doses of $\mathrm{CdCl} 2$ by a single SC injection significantly reduced sperm concentration and human corionic gonadotropin (hCG)stimulated serum T, at 14 days after treatment; conversely, a high dose of $\mathrm{CdCl} 2$ abolished hCG-stimulated serum $\mathrm{T}$ secretion and spermatogenesis, and reduced the weight of testes, epididymides and seminal vesicles [54]. An experimental in vivo study in rats showed that daily treatment with $\mathrm{CdCl} 225 \mathrm{mg} / \mathrm{L}$ in the drinking water for 1 month, affected the daily pattern of gonadotropins and $\mathrm{T}$ secretion [55]. Daily exposure of rats to $\mathrm{CdCl} 2$ in drinking water at doses corresponding to low, intermediate and high environmental doses, for 1, 4 or 8 weeks, produced a dose-dependent and time-dependent decrease in sperm motility [56]. Moreover, prolonged treatment with $\mathrm{Cd}$ in drinking water, even at low doses, caused pathological testis alterations, and affected fertility [57]. Similar results were obtained in male mice treated daily by oral gavage with $50 \mathrm{mg} / \mathrm{kg}$ body weight $\mathrm{CdCl} 2$ for 45 days; moreover, in this study, a significant decrease in sperm total count, spermatozoa nuclear maturity and serum $\mathrm{T}$ concentrations was reported [58]. Lastly, in treated animals, testes were atrophic with large areas of necrotic tissue, and lipid peroxidation was significantly increased [58]. The results of these studies suggest that $\mathrm{Cd}$ affects the development of the male reproductive system and, in particular, testis function, by compromising both spermatogenesis and semen quality, as well as endocrine function; the detrimental effects can occur at both high and low doses, and might be irreversible, if animals are exposed during fetal development up to pre-pubertal period.

\section{Mechanisms of cadmium reprotoxicity}

The molecular mechanisms driving the reprotoxicity of $\mathrm{Cd}$ have been mainly uncovered by experimental in vitro, ex vivo, and in vivo studies in animal models, although supporting human evidences have been also reported. Cd has been demontrated to affect spermatogenesis and/or semen quality and endocrine function, by different pathogenetic mechanisms. Cd severely affects testis structure, by damaging vascular endothelium and blood-testis barrier (BTB) integrity, and by inducing inflammation and apoptosis within the testis. Moreover, Cd exerts specific effects on testis cells, which include functional impairment of Sertoli and Leydig cells, and oxidative stress in somatic and germ cells, mainly mediated by mimicry and interference with essential ions, beyond apoptosis occurring in germ cells. The interference with selected signaling pathways and the interference with the epigenetic regulation of genes involved in the regulation of the reproductive function, have been hypothesized as additional mechanisms of Cdinduced reprotoxicity, but have not been specifically investigated. Lastly, disturbance of the hypothalamus-pituitary-gonadal axis is also reported after $\mathrm{Cd}$ treatment. A schematic representation of the proposed pathogenetic mechanisms underlying $\mathrm{Cd}$ reprotoxicity is reported in Fig. 1.

\subsection{Structural damage within the testis}

Experimental in vitro and in vivo studies in animals showed that Cd negatively affects testis vascular endothelium and BTB, there- fore resulting in testis damage at structural, and, consequently, functional level.

\subsubsection{Vascular endothelium damage}

A large body of evidences suggests that vascular endothelium might be one of the major targets of Cd intoxication, and that vascular damage may occur at relatively low Cd concentrations. In the testis, Cd was shown to specifically damage the internal spermatic artery with its testis and epididymal branches, and the pampiniform plexus [59], therefore increasing blood vessel permeability [60], which in turn determines fluid leakage into testis interstitium, followed by edema, hemorrhage, inflammation, hypoxia and, consequently, necrosis of the testis [61]. The detrimental effect of $\mathrm{Cd}$ on the vascular endothelium is due to structural, metabolic and functional damage of endothelial cells, and, at relatively high Cd doses, results in cell death. Cd was shown to affect endothelial cells by inducing a direct structural change in the adherens junctions among the endothelial cells of testis vessels [62]; in particular, Cd was shown to induce alterations in the expression and function of the calcium-dependent cell adhesion molecule vascular endothelial cadherin (VE-cadherin) at the cell-cell contacts, and a reorganization of the actin cytoskeleton [62]. In in vitro studies on human endothelial cells, Cd at low concentrations demonstrated a direct inhibitory effect on cell metabolism, cell migration, and tube formation, through a redistribution of VE-cadherin, and a decrease in nitric oxide production by the endothelial cells [63]. Moreover, $\mathrm{Cd}$ at high concentrations produced acidification and permeabilization of lysosomes, followed by the release of active DNAse II and DNA degradation, leading to programmed necrosis in endothelial cells [62]. A specific metal ion transporter, ZIP8, has been identified as an enhancer of $\mathrm{Cd}$ uptake by vascular endothelial cells in the testis of mice, and its expression has been found to be associated to sensitivity to Cd-induced testis injury [64]. Indeed, ZIP8 is notably expressed by the vascular endothelial cells in the testis of Cd-sensitive strains, but not Cd-resistant strains, of mice [64], thus reinforcing the hypothesis that this transporter might be implicated in the differential susceptibility of animals to $\mathrm{Cd}$ toxic effects on vascular endothelial cells. The results of these studies suggest that vascular endothelium damage resulting in necrosis within the testis, may ultimately affect spermatogenesis and testis endocrine function. The deleterious effects of $\mathrm{Cd}$ on the testis vascular endothelium are depicted in Fig. 2.

\subsubsection{Blood-testis barrier disruption}

The BTB is a unique structure, formed by the tight junction of Sertoli cells, which bisects the seminiferous epithelium into the basal and the apical compartments, by segregating meiotic and post-meiotic germ cells behind the barrier, in the apical compartment, therefore preventing not only the passage of cytotoxic agents from the blood into the seminiferous tubules, but also the passage of antigenic products of germ cell maturation into the circulation, which might generate autoimmunity against germ cells [65]. Although BTB is tightly sealed, it is not a static ultrastructure, but undergoes massive remodeling during spermatogenesis in order to permit the transit of spermatocytes, meanwhile maintaining the barrier protecting from toxic and immunological factors [65]. A damage of the BTB is associated to germ cells loss and reduced sperm total count, which determine subfertility or infertility conditions [65]. Cd has been shown to dose-dependently affect BTB integrity, by inhibiting the establishment or inducing the disruption of the tight junctions among rat Sertoli cells in vitro, through a down regulation of occludin, a tight junctions integral membrane protein [66]; this effect was counteracted in vitro by the addition of $\mathrm{T}$ to cultured cells, which induced a mild but significant increase in the expression of occludin, thus enhancing the tightness of the junctions [66], these results suggest that 


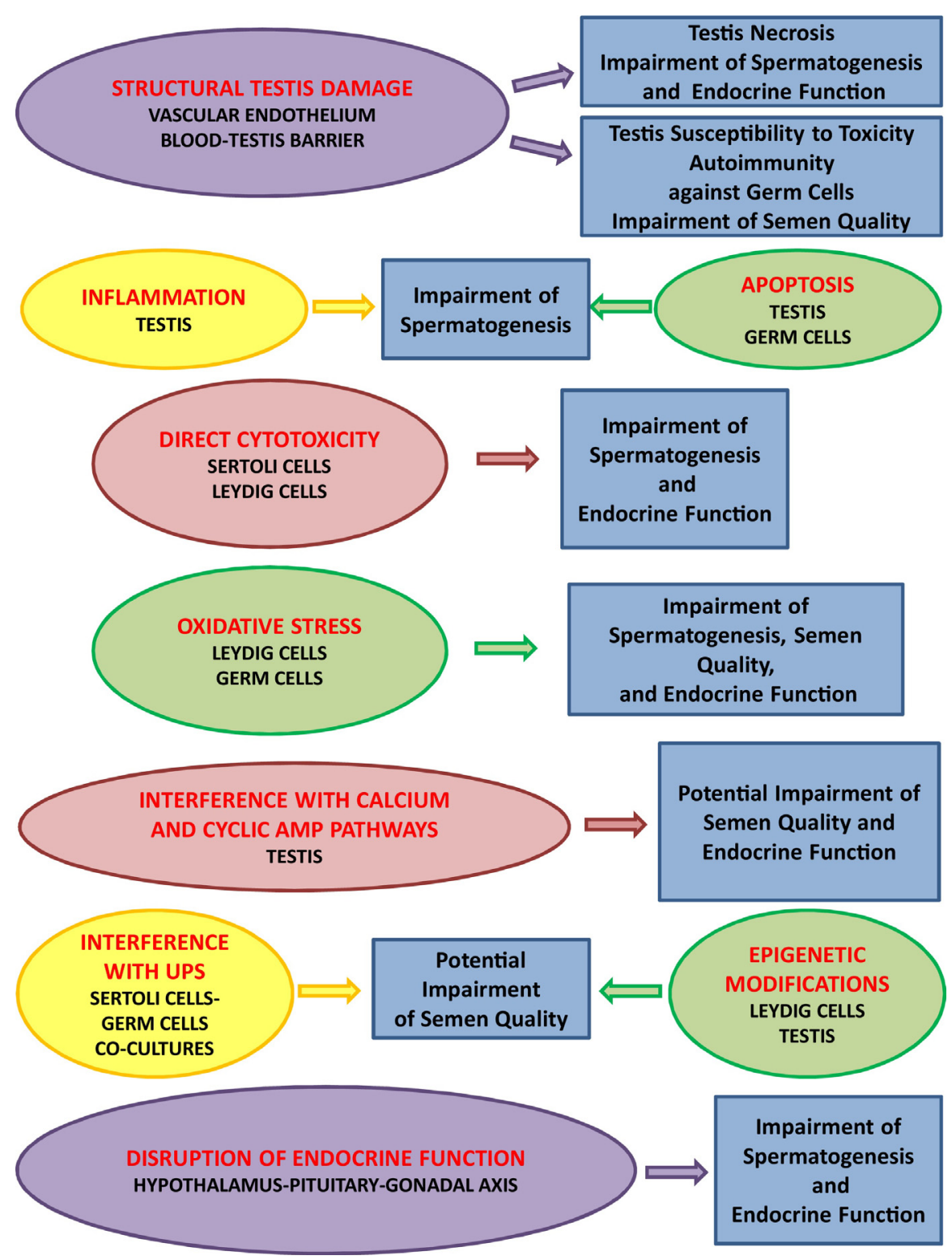

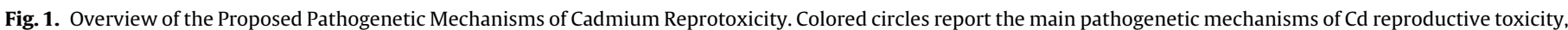

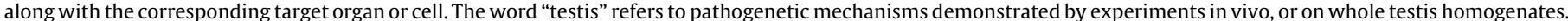

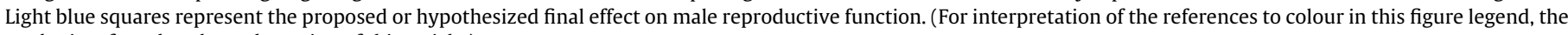
reader is referred to the web version of this article.)

Cd-induced downregulation of occludin might be mediated by interference of Cd with T concentration. Specific signaling mediators, such as the p38 mitogen-activated protein kinase, and the transforming growth factor $\beta 2$ and $\beta 3$ molecular pathways, which are involved in occludin production and in the BTB assembly [65], have been found to be implicated in Cd-induced destabilization of the BTB [67-69]; indeed, Cd treatment was shown to decrease occludin expression, coinciding with an imbalance in the activation of these mediators, in Sertoli cells $[67,69]$. In an in vitro study on rat Sertoli cells, another mechanism for Cd-driven disruption of BTB was proposed, consisting in the re-localization of occludin and of the protein involved in cell-cell adhesion, denominated focal adhesion kinase (FAK), at the Sertoli-Sertoli interface, an effect mediated by the disturbance of endocytosis and, perhaps, recycling [68]. This study demonstrated that $\mathrm{CdCl} 2$ treatment induced endocytosis of occludin and FAK, which were removed from the Sertoli-Sertoli interface and transported towards the cytoplasm; conversely, the effect on protein recycling was speculated by authors, and studies specifically addressing this hypothesis are lacking [68]. The results of these studies suggest that BTB disruption may mediate the toxic effect of Cd on semen quality, by possibly enhancing testis susceptibility to toxic substances, as well as determining the development of autoimmunity against germ cells. The deleterious effects of Cd on the BTB are depicted in Fig. 3.

\subsection{Inflammation within the testis}

An experimental in vivo study in animals showed that $\mathrm{Cd}$ exposure induced testis inflammation [70]. Cd-loaded rats developed signs of testis inflammation, with significantly increased expression of inflammation markers, including inducible nitric oxide synthase, cyclooxygenase-2, tumor necrosis factor- $\alpha$, nuclear factor-kB, and heme oxygenase-1, in testis homogenates [70]. Cdinduced testis inflammation resulted in widespread necrosis and vacuolization of the seminiferous epithelium cells, together with 


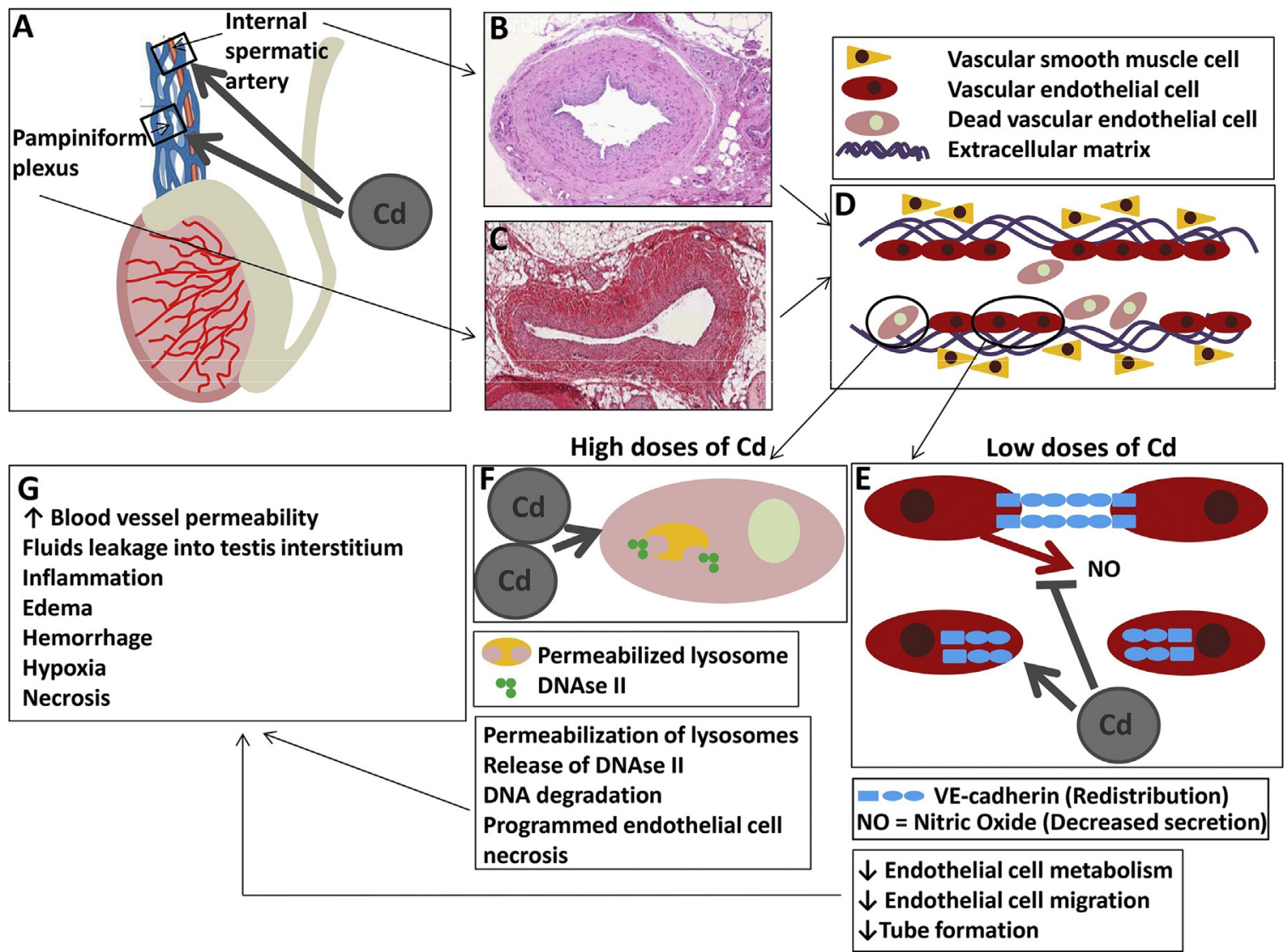

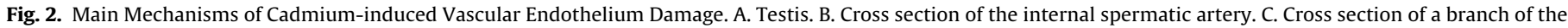

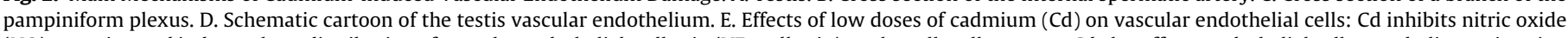

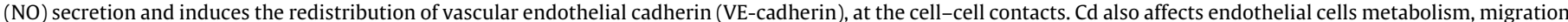

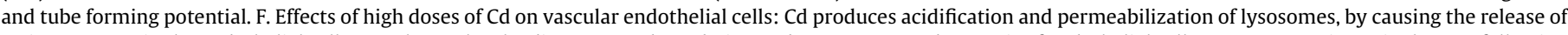

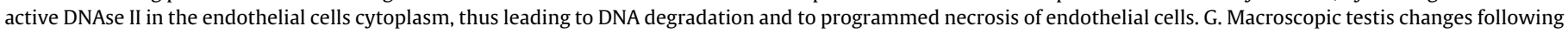
Cd treatment.

interstitial tissue edema and hemorrhage [70]. These pathological changes were associated to an impairment of spermatogenesis [70]. The results of this study suggest that inflammation may mediate the toxic effect of $\mathrm{Cd}$ on spermatogenesis. The effects of $\mathrm{Cd}$ on inflammation are depicted in Fig. 4.

\subsection{Apoptosis within the testis}

Experimental in vivo studies in animals showed that Cd was able to perturb the balance between cell proliferation and apoptosis, by suppressing the expression of the anti-apoptotic gene B-cell lymphoma $2(\mathrm{Bcl} 2)$ and by enhancing the expression of the pro-apoptotic genes p53 and Bcl2-Associated X (Bax), in testis homogenates, thus enhancing the apoptotic process, in adult male rats [71]. Similar effects were demonstrated in mice germ cells, since $\mathrm{Cd}$ treatment strongly induced germ cells apoptosis, driven by the downregulation of the anti-apoptotic protein B-cell lymphomaextra large (Bcl-XL), and the upregulation of the pro-apoptotic proteins Bax and caspase-3 [72]. Further studies in mice demonstrated that both mitochondrial pathway and endoplasmic reticulum pathway are involved in Cd-induced germ cells apoptosis [73]. The results of these studies suggest that apoptosis of germ cells within the testis may mediate the toxic effect of $\mathrm{Cd}$ on spermatogenesis. The effects of Cd on apoptosis are depicted in Fig. 4.

\subsection{Direct cytotoxicity on testis cells}

Experimental in vitro studies in animals showed that Cd exerts direct cytotoxicity within the testis, mainly targeting two specific cell populations, the Sertoli cells and the Leydig cells, with consequent impairment of spermatogenesis and endocrine function. Sertoli cells were shown to be more sensitive to Cd toxicity, and show the major structural and functional alterations upon Cd exposure, even at doses that do not result in visible damage within the testis [74]. The direct detrimental effects of Cd on Sertoli and Leydig cells are summarized in Fig. 5.

\subsubsection{Sertoli cells}

An in vitro study on rat Sertoli cells culture showed that $\mathrm{CdCl} 2$ adversely affected cell viability, with a dose-dependent and timedependent trend $[74] . \mathrm{CdCl} 2$ toxicity was also confirmed in superior mammals, particularly, in in vitro studies on Sertoli cells isolated from pre-pubertal pig testis [75]. The results showed that $\mathrm{CdCl} 2$ treatment induced an impairment of Sertoli cells function, as demonstrated by the reduction in INH-B and anti-Mulleran hormone $(\mathrm{AMH})$ secretion, and by the disruption of FSH receptor responsiveness, as measured by $\mathrm{E}_{2}$ production, and induced Sertoli cells apoptosis [75]. The results of these studies suggest that cytotoxicity on Sertoli cells may mediate the toxic effect of $\mathrm{Cd}$ on spermatogenesis.

\subsubsection{Leydig cells}

An in vitro study on rat Leydig cells culture showed that $\mathrm{CdCl} 2$ adversely affected cell viability, with a dose-dependent and timedependent trend [74]. Moreover, Cd compromised Leydig cells function, as demonstrated by the reduction of $\mathrm{T}$ concentrations in culture supernatants of treated cells [76,77]. Different in vitro studies in rats demonstrated that, under Cd influence, Leydig cells 


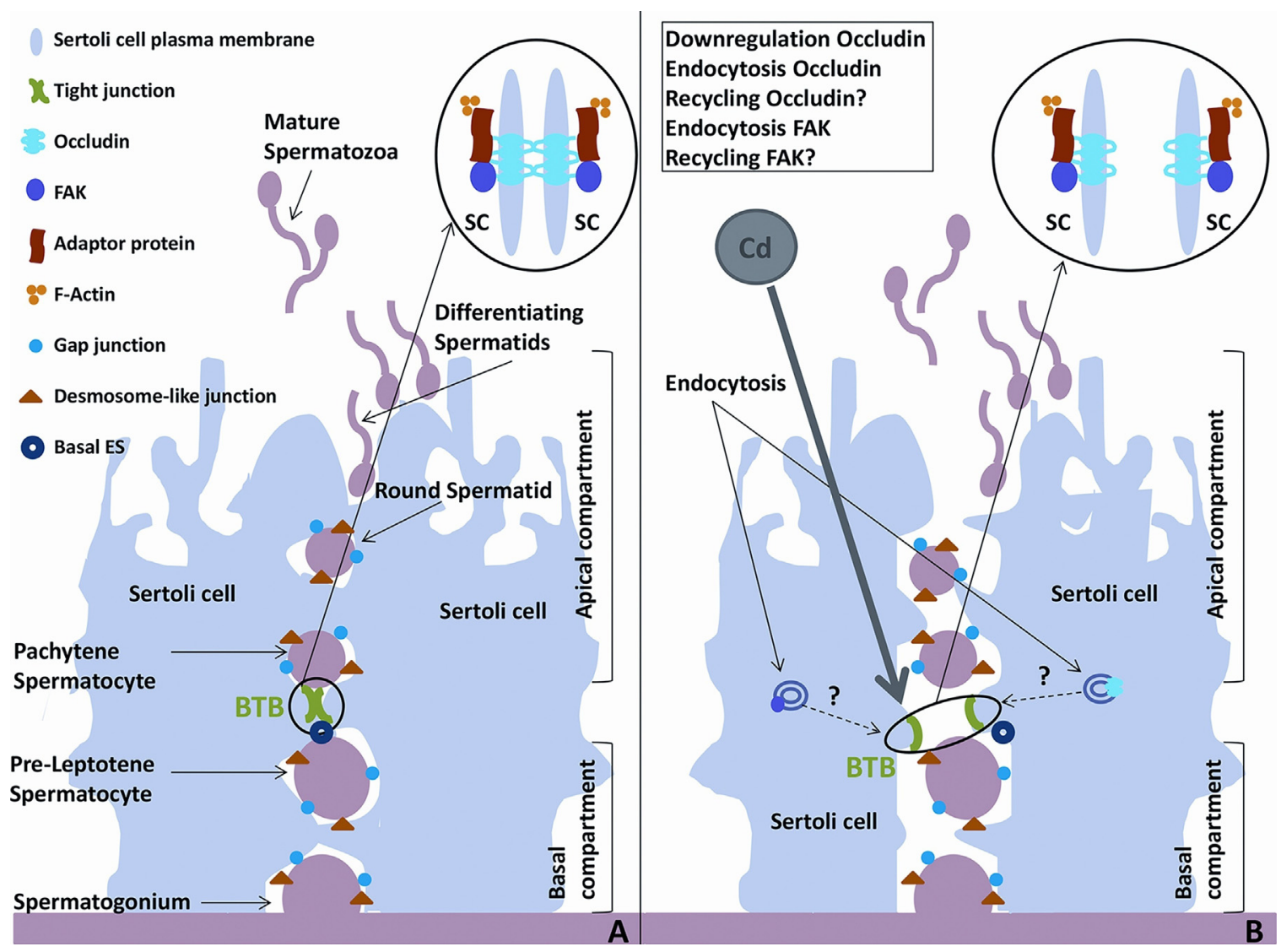

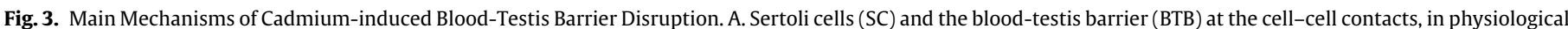

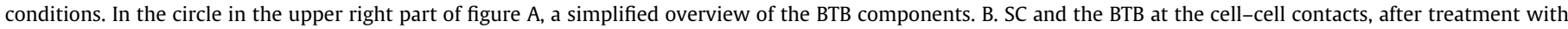

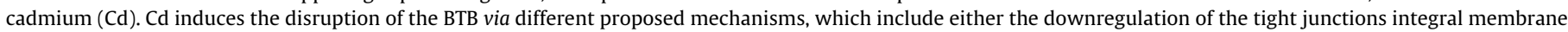
protein occludin, and/or the disturbance of the endocytosis and recycling balance of occludin and focal adhesion kinase (FAK).

responsiveness to hCG stimulation was reduced, as demonstrated by the reduction of $\mathrm{T}$ production $[78,79]$. The results of these studies suggest that cytotoxicity on Leydig cells may mediate the toxic effect of Cd on testis endocrine function.

\subsection{Mimicry and interference with essential ions: a focus on zinc and selenium}

Experimental in vitro, ex vivo, and in vivo studies in animals support that mimicry and interference with $\mathrm{Zn}$, as well as interference with Se, might play a role in Cd-induced reprotoxicity. Cd ions mimic the action of different ions, including essential ions, which display a similar chemical structure, a phenomenon defined as mimicry [80]. Two different mechanisms of mimicry may occur: ionic and molecular. The ionic mimicry is the ability of free Cd ions to imitate different chemical species, for instance the ability to enter the cell by means of membrane carriers or channels, deputed to the uptake of different ions [80]; the molecular mimicry is the ability of $\mathrm{Cd}$ ions to displace different ions from their position in biological molecules [80]. As a result of these mimicry mechanisms, downstream effects of $\mathrm{Cd}$ might include the modulation of ions concentration within the cell, and the structural modification of ions target molecules, with consequent inhibition of their biological actions. Interference of $\mathrm{Cd}$ with essential ions include modifications of ions absorption, bioavailability, tissue distribution, and excretion [80]. Mimicry phenomena have been extensively described between $\mathrm{Cd}$ and $\mathrm{Zn}$, whereas interference has been described between $\mathrm{Cd}$ and $\mathrm{Zn}$, and between $\mathrm{Cd}$ and Se. The mimicry and interference mechanisms between $\mathrm{Cd}, \mathrm{Zn}$, and Se, are depicted in Fig. 6.

\subsubsection{Mimicry and interference with zinc}

Several experimental studies in animals and evidences from human subjects exposed to $\mathrm{Cd}$, showed mimicry and interference between $\mathrm{Cd}$ and $\mathrm{Zn}$, at multiple levels. $\mathrm{Zn}$ is an essential element involved in an impressive number of functions, including male reproduction, with impact on spermatogenesis, semen quality and, ultimately, fertility. Indeed, adequate $\mathrm{Zn}$ concentrations are necessary for proper spermatogenesis, probably due to its effects on $\mathrm{T}$ synthesis, and seminal plasma $\mathrm{Zn}$ concentration showed a positive correlation with optimal semen quality [81-84]. Zn might behave as co-factor at the active sites of metabolic enzymes, such as hydrolases, lyases, dehydrogenases, and, in combination with different metals, antioxidant enzymes, such as superoxide dismutase, or might behave as a regulatory element in the action of kinases or phosphatases. Furthermore, $\mathrm{Zn}$-finger domains mediate protein-protein or protein-nucleic acid binding [85]. Experimental evidences denote that $\mathrm{Cd}$ uptake into target cells may occur by ionic mimicry at the ionic binding site of several transporters, including $\mathrm{Zn}$ transporters [80,86]. In vitro studies on Leydig cells isolated from rat testis and in vivo studies in mice demonstrated that, in the testis, the major route of entry of $\mathrm{Cd}$ might be a $\mathrm{Zn}$ transporter, since Zn selectively blocked Cd uptake [64,87-91]. A putative mechanism of Cd entry in the cells, including testis cells, is represented by ionic mimicry at the transporters belonging to the ZIP family of Zn transporters [64,87-91]. Cd intracellular concentration may rise by ZIP Zn transporters-mediated uptake from extracellular, as well as from intracellular vesicles milieu, in a $\mathrm{Zn}$-competitive fashion, by potentially decreasing $\mathrm{Zn}$ intracellular concentration [64,90]; conversely, the effects of $\mathrm{Cd}$ on $\mathrm{ZnT}$ family of $\mathrm{Zn}$ transporters, that are responsible for $\mathrm{Zn}$ efflux from the cytosol and $\mathrm{Zn}$ uptake into intra- 


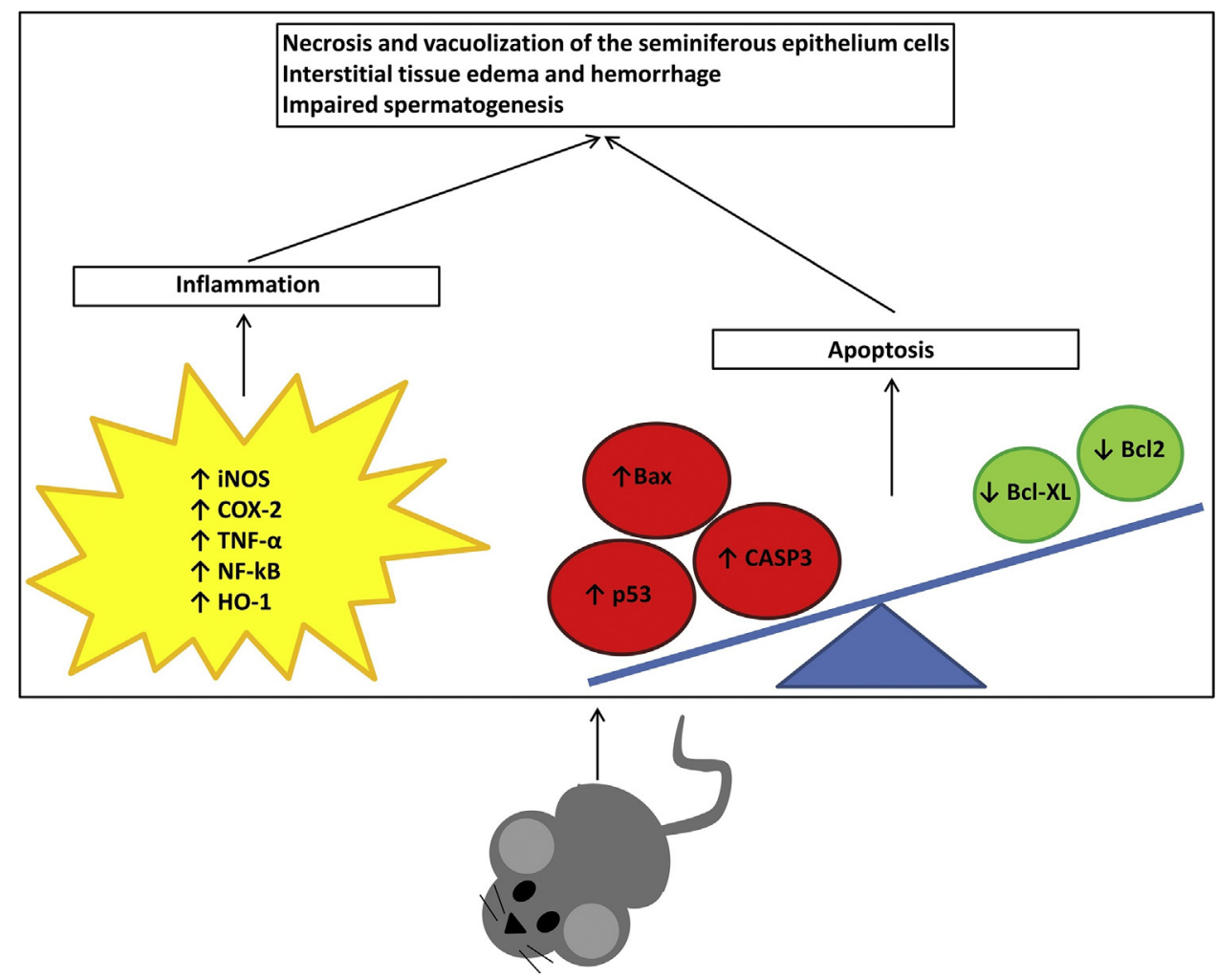

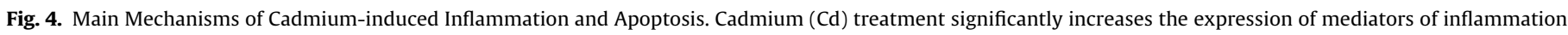

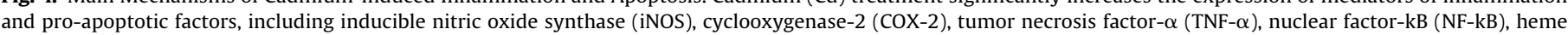

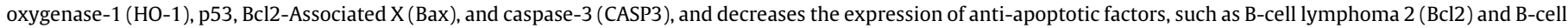

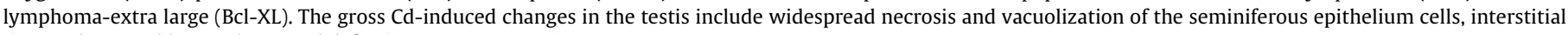
tissue edema and hemorrhage, and defective spermatogenesis.

cellular vesicles in many organs, including testis, are unknown [92]. Interference between $\mathrm{Cd}$ and $\mathrm{Zn}$ occurs at multiple levels: intestinal absorption, bioavailability, tissue distribution, and faecal and urinary excretion $[14,15,93]$. In ex vivo isolated rat intestine preparations, treatment with $\mathrm{Cd}$, even at low levels of exposure, was demonstrated to inhibit $\mathrm{Zn}$ intestinal absorption [94]; moreover, in a study on human subjects exposed to $\mathrm{Cd}$, bpCd was associated to a significant decrease, despite remaining within the normal range, of serum $\mathrm{Zn}$ concentrations [95]. On the other hand, $\mathrm{Zn}$ was shown to exert protective effects from Cd poisoning, by reducing its intestinal absorption and retention, as confirmed by experimental in vivo studies in birds exposed to $\mathrm{Cd}$ and fed adequate-Zn or low-Zn diets [96], and by reducing Cd accumulation in blood and in several organs and tissues, including the testis [97-99]. Cd and Zn share similar chemical properties, and mainly bind to biological macromolecules containing sulphydryl, hydroxyl and nitroxyl groups; although $\mathrm{Cd}$ ion is larger than $\mathrm{Zn}$ ion, $\mathrm{Cd}$ has a higher affinity for sulphydryl-containing proteins and nucleic acids, and quite easily substitutes for $\mathrm{Zn}$ through molecular mimicry, in the presence of excess Cd [100]. On the basis of similarities with $\mathrm{Zn}$, $\mathrm{Cd}$ can potentially interfere with several $\mathrm{Zn}$-mediated biological processes, including the reproductive function. In vivo studies on rats demonstrated that co-treatment with $\mathrm{Zn}$ protected the animals from the Cd-induced vascular injury within the testis [59], and attenuated the severe pathological changes and the oxidative stress induced by Cd within the testis [101-103]. Moreover, cotreatment with $\mathrm{Zn}$ reversed the detrimental effects of Cd on plasma and seminal T concentrations, and on spermatogenesis [101-103].

\subsubsection{Interference with selenium}

Several experimental studies in animals showed that Cd might interfere with Se at multiple levels. Se is an essential element with pivotal functions in the maintenance of male reproduction, by influencing structure of the testis, spermatogenesis, semen quality and, ultimately, fertility [84,104]. The adequate dietary intake of Se, in both organic and inorganic form, is required for proper protection of fertility, since Se or selenoproteins deficiency or excess results in oxidative stress [105], abnormality of spermatozoa maturation and morphology [106-108], and pathological alterations of the testis [109-111]. In humans, seminal plasma content of Se was reduced in male partners of infertile couples [112]. Moreover, at optimal seminal plasma concentration, Se was positively correlated to sperm total count, concentration, motility and vitality, and negatively correlated to the biomarker of oxidative stress 8-OHdG [34,113]; however, different studies failed to confirm these correlations $[114,115]$, probably because of different study population or methodology, or because of different ranges of Se detected in the different studies, leading to inconsistencies, due to hormesis mechanism. Few studies attempted to determine the interference between $\mathrm{Cd}$ and Se, in animal models; an in vivo study in rats showed that $\mathrm{Cd}$ at non toxic but environmentally relevant concentration did not affect Se intestinal absorption or tissue distribution in several organs, including testis, particularly in case of adequate Se dietary supplementation [116]; however, at toxic doses of Cd, a significant decrease in serum concentrations, and an increase in urinary excretion of Se were noted [117]. Conversely, the addition of Se to a diet containing $\mathrm{Cd}$ reduced $\mathrm{Cd}$ renal excretion, and increased $\mathrm{Cd}$ deposition in the testis, although it prevented $\mathrm{Cd}$-induced testis toxicity, by means of the immobilization of $\mathrm{Cd}$ in $\mathrm{Cd}$-Se protein complexes [118-122]. Indeed, studies in rats showed that the pretreatment with Se, or the co-treatment with Se and Cd, but not Se treatment after Cd administration, prevented Cd-driven testis vascular damage [123], testis atrophy and necrosis, as well as testis dysfunction [124-127], as measured by spermatogenetic activity, 

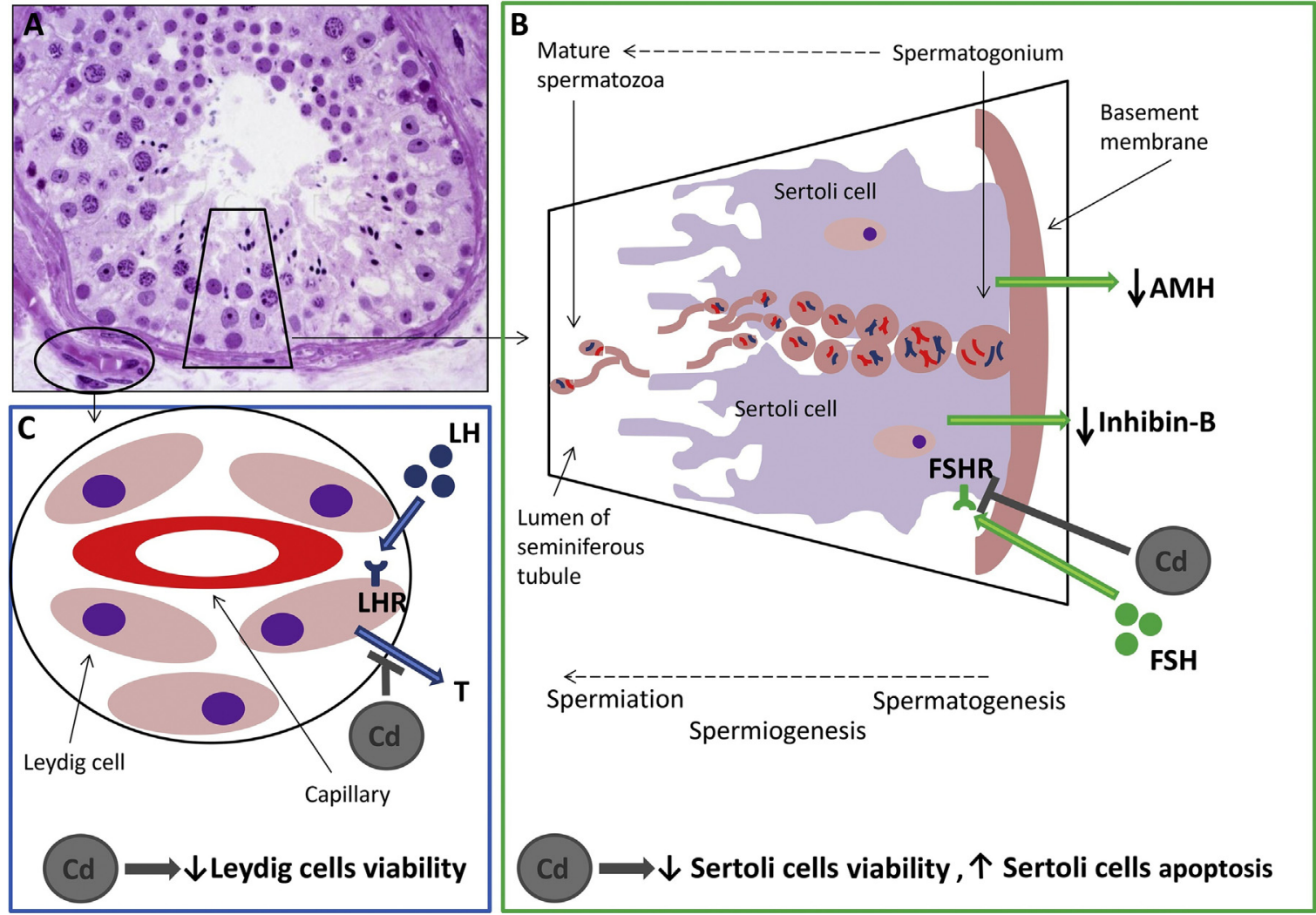

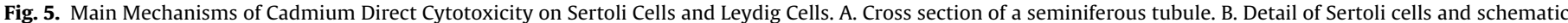

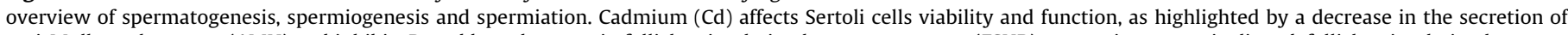

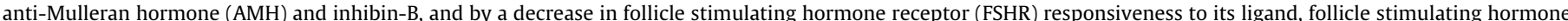

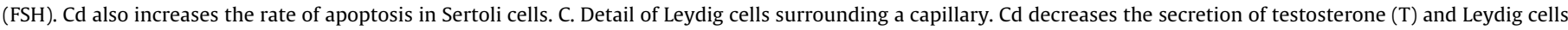
viability. Luteinizing hormone (LH); Luteinizing hormone receptor (LHR).

steroidogenic acute regulatory protein (StAR), $3 \beta$ - hydroxysteroid dehydrogenase, and $17 \beta$-hydroxysteroid dehydrogenase activity, and $T$ production $[128,129]$, suggesting that the proper concentration of Se should be maintained in order to prevent Cd-induced damage [130]. Moreover, in in vitro studies on ram spermatozoa, Se was shown to improve the Cd-driven impairment of sperm motility and oxygen consumption [131]. The mentioned beneficial effects of Se treatment in Cd-poisoning models were accompanied by a striking protective effect on the anti-oxidative defense system, which prevented Cd-driven oxidative damage and lipid peroxidation. Cd-induced oxidative damage is primarily driven by interference between $\mathrm{Cd}$ and $\mathrm{Se}$, with major affected targets being the glutathione (GSH) system and, particularly, the GSH peroxidase (GSH-Px)[128,130,132-136]. Indeed, Se is a structural component of selenoproteins, comprising antioxidant enzymes, such as GSH-Px $[137,138]$, which catalyzes the reduction of hydrogen peroxide and organic peroxides, including phospholipids peroxides. Optimal Se concentrations are protective against oxidative stress, and Se deficiency determines a decrease in GSH-Px activity and an increase in hepatic GSH-S-transferase activity $[139,140]$; therefore, the interference of $\mathrm{Cd}$ on Se concentrations might be responsible of the observed effects on the induction of oxidative damage.

In summary, the mimicry and interaction between $\mathrm{Cd}$ and essential ions, such as $\mathrm{Zn}$ and Se, and competition for transporters, enzymes, and molecules involved in important ion-mediated biological processes, could partially account for the different response or susceptibility thresholds to $\mathrm{Cd}$. These evidences suggest that the maintenance of adequate concentrations of these essential ions and their dietary supplementation could contribute to protect testis and reproductive function from $\mathrm{Cd}$ toxicity.

\subsection{Oxidative stress}

Experimental in vitro and in vivo studies in animals demonstrated that the induction of oxidative stress is a well-established mechanism of reprotoxicity, particularly directed to Leydig cells and germ cells, including spermatozoa. $\mathrm{Cd}$ is implicated in the increase of reactive oxygen species (ROS) and in the induction of oxidative stress through indirect mechanisms: the first mechansm consists in Cd binding to sulfhydryl groups of ROS scavengers, which determines an alteration of their regulatory activity $[141,142]$, whereas the second mechanism consists in the interference with essential ions required for ROS scavengers function, resulting in depletion of GSH, presumably due to the production of ROS at a rate that exceeds the ability to regenerate reduced GSH; both processes result in the production of ROS, such as superoxide ion, hydrogen peroxide and hydroxyl radicals [141,142]. This indirect Cd-induced increase in ROS content leads to excess of protein oxidation, lipid peroxidation, DNA damage and, ultimately, cell death $[143,144]$. The effect of Cd on ROS scavengers is mainly mediated by the displacement of $\mathrm{Zn}$ and $\mathrm{Cu}$ from antioxidant enzymes, a molecular mimicry mechanism which results in conformational changes and impairment in the activity of the enzymes; moreover, the increased $\mathrm{Cu}$ concentration in the cell also induces ROS production [145-147]. A different mechanism of Cd-induced oxidative stress is related to Cd interference with Se, and consequent interference with reduced GSH, oxidized GSH, GSH-Px, GSH reductase (GSH-Rx) and catalase (CAT) activities. Among the four GSH-Px isoforms, GSH-Px4 is particularly expressed in male reproductive system [148], and its deregulation has been implicated in reproductive disorders $[149,150]$. Cd was shown to interfere with Se 


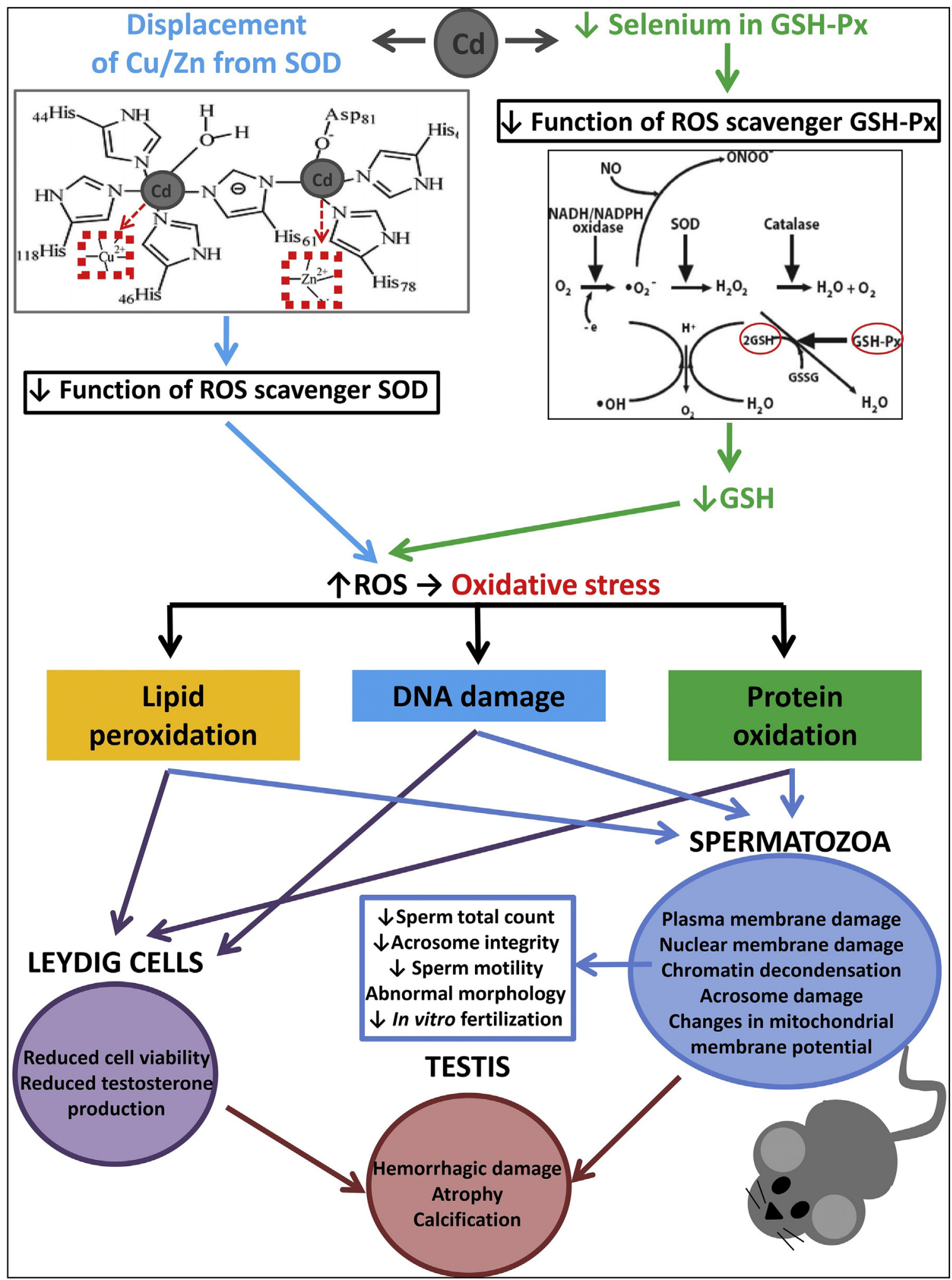

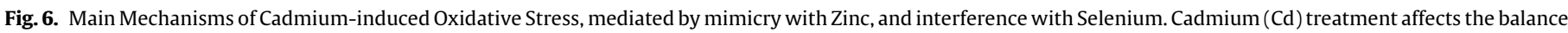

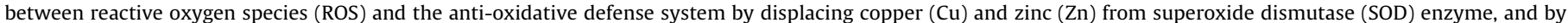

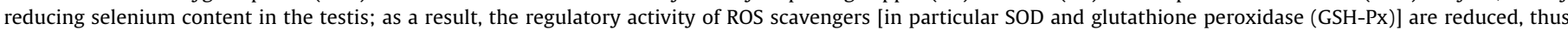

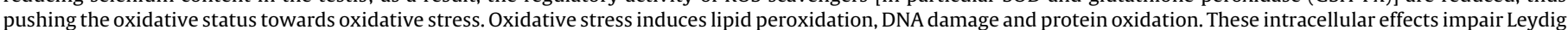

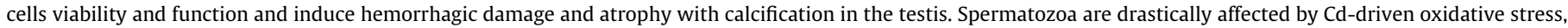

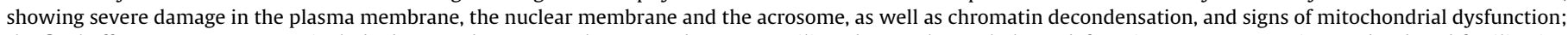

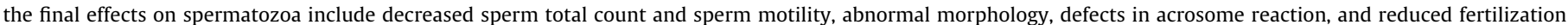
potential. 
metabolism by reducing its serum and testis concentrations, thus affecting the activity of GSH-Px, and increasing lipid peroxidation; in in vivo studies in animals, these effects were prevented by the pre- or co-treatment with Se $[128,132,134,135,150,151]$. Several studies investigated these Cd-driven oxidative stress mechanisms in animal models. In vivo acute treatment with $\mathrm{CdCl} 2$ caused severe hemorrhagic damage in the testis and subsequent testis atrophy with calcification. An early event after Cd treatment was an increased production of hydrogen peroxide, and a remarkable elevation in lipid peroxidation and DNA damage in Leydig cells, as well as in spermatocytes, showing an increased number of chromosome abnormalities and atypical mitoses, as a result of Cd-induced imbalance in reduced GSH, oxidized GSH, GSH-Px, GSH-Rx and CAT activities [77,152,153]. In mice treated with a single SC injection of 1,2 and $3 \mathrm{mg} / \mathrm{kg}$ body weight of $\mathrm{CdCl} 2$, the earliest deleterious effects of $\mathrm{CdCl} 2$ were mainly exerted on sperm motility, morphology and acrosome reaction; the later negative effects were elicited on sperm total count [154]. The consequences of oxidative stress are particularly dramatic in oxidative damage-sensitive cells, such as spermatozoa, in particular when lipid peroxidation within plasma membrane occurs, by strongly contributing to the reduction of sperm motility and fusogenic potential with the oocyte $[52,155,156]$; moreover, oxidative stressinduced DNA damage in spermatozoa is a well documented cause of male infertility, since it elicits the transfer of abnormal genomic information to the embryo, by increasing the incidence of miscarriage and offspring diseases [157,158]. A large number of studies investigated in vitro the direct effects of $\mathrm{Cd}$ on the oxidative status, and its genetic, morphological, and functional consequences in spermatozoa from different animal models [159-162]. In vitro Cd treatment significantly increased ROS concentrations over time in spermatozoa, by altering the total antioxidant capacity; the oxidative damage resulted in increased lipid peroxidation, and protein and DNA damage in spermatozoa. The effects of oxidative damage at lower $\mathrm{Cd}$ doses induced a dose-dependent reduction of total motility and progressive forward motility [159,161,162]. At higher Cd doses, however, the effects of Cd-induced oxidative damage were mainly reflected by abnormal sperm morphology and several ultrastructural changes: spermatozoa membrane integrity was significantly compromised, as spermatozoa displayed a wrinkled surface which became partly or completely dissolved; the nuclear envelope became wrinkled and chromatin showed different patterns of condensation and irregularities; the acrosomal membrane was damaged and acrosome incomplete; spermatozoa showed small heads, loss of flagellum, broken flagellum, or flagellum with abnormal morphology, and cytoplasmic drop retention [159-162]. These profound Cd-induced pathological changes ultimately determined a dramatic impairment of in vitro fertilization, as measured by the percentage of cleaved oocytes, at 40-42 h after insemination [162]. Correlation studies in bovine semen and spermatozoa demonstrated that $\mathrm{Cd}$ is negatively correlated to GSH and CAT, and positively correlated to lipid peroxidation; moreover, samples exhibiting the highest $\mathrm{Cd}$ content had reduced sperm motility [163]. In summary, the results of these studies suggest that oxidative stress may mediate the toxic effect of $\mathrm{Cd}$ on spermatogenesis and semen quality, besides the endocrine function, and eventually induce serious damage of the testis. The main mechanisms of $\mathrm{Cd}$-induced oxidative stress are reported in Fig. 6.

It is noteworthy that, besides the oxidative DNA damage affecting DNA integrity, Cd was shown to exert different genotoxic actions affecting both DNA sequence and gene expression; these actions mainly comprise epigenetic modifications, and a poor mutagenic activity, which are mostly, but not exclusively, related to Cd-driven carcinogenesis [164-169].

\subsection{Interference with signaling pathways}

Experimental in vitro and in vivo studies in animals and evidences from human subjects exposed to Cd suggested that specific mechanisms of $\mathrm{Cd}$ reprotoxicity might be linked to precise downstream signaling pathways, which include the ubiquitin proteasome system (UPS) signaling pathway, and the calcium and cyclic AMP pathways.

\subsubsection{Ubiquitin proteasome system signaling pathway}

The UPS is a complex and highly conserved pathway that is central to the determination of proteins fate, since it mediates the proper and timely degradation of specific proteins, therefore influencing several cell functions [170]. UPS drives the necessary cell plasticity, which is functional to Sertoli cell-germ cell interactions and spermatozoa final maturation, and tags abnormal spermatozoa for elimination, thus exerting puzzling actions in both spermatogenesis and spermatozoa fertilization [171,172]. In an in vitro study on primary rat Sertoli cell-germ cell co-cultures, Cd was shown to dose- and time-dependently inhibit proteasome activity, and to induce an enrichment in high-molecular weight polyubiquitinated proteins [173]. These Cd-induced alterations in UPS functioning were accompanied by the activation of stress signaling pathways, in particular by increasing the phosphorylated form of the stress-activated protein kinase/c-Jun N-terminal kinase (SAPK/JNK) and p38 [173]. UPS is responsible for spermatozoa quality control mechanisms occurring in the mammalian and human epididymis, which is the site of spermatozoa maturation and storage [172]. Defects in UPS functioning have been proposed to be involved in the persistence of abnormal spermatozoa in the ejaculate, therefore contributing to the reduction of male fertility [172]; therefore, although the relationship between Cd treatment and UPS downstream signaling has not been further addressed, it can be speculated that the Cd-induced disturbance of UPS may affect semen quality in humans, by preventing the elimination of damaged spermatozoa.

\subsubsection{Calcium and cyclic AMP signaling pathways}

The interference of $\mathrm{Cd}$ with calcium homeostasis, signaling and transcriptional activity [174,175], as well as the Cd-induced modulation of calcium channel variants expression [56,176], may be considered as additional causes of Cd-induced reprotoxicity, since calcium is a crucial mediator involved in the regulation of sperm motility and acrosome reaction [177]. Moreover, calcium and cyclic AMP pathways are strictly and reciprocally linked, thus the effects of Cd on calcium signaling also indirectly contribute to determine molecular changes downstream to cyclic AMP, which is also implicated in the regulation of reproductive function [178,179].

$\mathrm{Cd}$ is likely to exert part of its detrimental effects on testis and germ cells by means of inappropriate activation of the calciumcalmodulin-calcineurin pathway. Few in vivo studies focused on this action: Cd was shown to bind to calmodulin [180], and Cddriven testis damage was effectively prevented by calmodulin $[181,182]$ and calcineurin [183] inhibitors, in mouse and rat animal models of Cd poisoning. High-voltage and low-voltage activated calcium channels provide a voltage-gated route of calcium influx into the cells. L-type and T-type voltage-dependent channels were identified in spermatozoa [184]. Whether the T-type or L-type channels trigger more potently the acrosome reaction is strongly debated: some authors argue that T-type calcium channels are the major conductors of calcium in spermatozoa [185,186], whereas some authors emphasize the role of L-type channels in calcium conductance [187-190], sperm motility [191], and acrosome reaction. L-type voltage-dependent calcium channels were proven to be permeable to Cd [192], as demonstrated by the reduction of 
intracellular Cd uptake and accumulation, by treatment with selective channels inhibitors [193], suggesting that these channels could be involved in $\mathrm{Cd}$ toxicity in the testis. Moreover, evidences in human subjects exposed to Cd [176], and in vivo studies in rats treated with $0,5,50$ or $100 \mathrm{mg} / \mathrm{L}$ of $\mathrm{Cd}$ in drinking water [56], demonstrated that $\mathrm{Cd}$ exposure determined the expression of alternatively spliced variants of L-type voltage-dependent calcium channels in the testis, and that deletions in L-type channels may alter calcium channel functions. The expression of channels splicing variants, with deletions in exons 7 or 8 , correlates to testis Cd burden and apoptosis in infertile men with varicocele [176]. L-type calcium channels localize to the spermatozoa tail [194,195], and are involved in sperm motility [196,197]; therefore, Cd may exert its detrimental effect on sperm motility by promoting the expression of alternative splicing variants with altered channel features.

Cyclic AMP is involved in nearly the totality of the male reproductive functions, including the synthesis and secretion of gonadotropin-releasing hormone and gonadotropins, the regulation of testis function, and the functionality of spermatozoa [178]. Cd effects on cyclic AMP pathway have been assessed in testis homogenates from Cd-treated animals, and the local effects on testis function have been investigated. In vivo studies in rats demonstrated that acute treatment with $\mathrm{CdCl} 2$ significantly reduced the concentration of cyclic AMP in testis homogenates [198]. Conversely, chronic treatment with daily injections of $\mathrm{CdCl} 2$ ( $1 \mathrm{mg} / \mathrm{kg}$ body weight) for 45 days did not change the endogenous amounts of cyclic AMP concentration in testis homogenates, since both adenylate cyclase and phosphodiesterase activities, which catalize the production and elimination of cyclic AMP, respectively, were strongly induced by $\mathrm{CdCl} 2$ [199]; however, the cyclic AMP-dependent and cyclic AMP-independent kinases were significantly depressed in testis homogenates from these animals [199]. Discontinuation of treatment returned adenylate cyclase and cyclic AMP-dependent kinase activities to baseline levels; nevertheless, phosphodiesterase activity was not restored within the testis, resulting in a decreased endogenous concentration of cyclic AMP, suggesting that at least some of the Cd-induced changes on cyclic AMP pathway were permanent, within the experimental timing [199]. Besides the direct alterations on cyclic AMP pathway, Cd also induces indirect changes in cyclic AMP metabolism, by inducing improper calcium-calmodulin activation, which in turn determines the activation of phosphodiesterase [179,200]. These evidences suggest that $\mathrm{Cd}$ treatment affects cyclic AMP metabolism in the testis, with some of these changes being permanent, although the downstream biochemical effects of such alteration have not been fully demonstrated. It has been proposed that, in the testis, Cd-induced changes in cyclic AMP metabolism might regulate gene expression by means of altered cyclic AMP-dependent phosphorylation of nucleoproteins by protein kinases, thus impairing testis function and contributing to the observed decrease of testis weight [198,199]. In summary, the results of these studies suggest that interference with calcium and cyclic AMP pathways may potentially mediate the toxic effect of $\mathrm{Cd}$ on semen quality and testis endocrine function.

\subsection{Interference with epigenetic gene regulation}

Experimental ex vivo and in vivo studies in animals, and studies in human subjects exposed to $\mathrm{Cd}$, highlighted that $\mathrm{Cd}$ might exert multiple epigenetic effects after both prenatal and postnatal exposure, and these changes might be hypothesized to affect male fertility. Epigenetic modifications modulate gene expression by means of transcriptional and translational effects. The major epigenetic mechanisms are DNA methylation, which is mediated by DNA methyltransferase (DNMT), histone modifications, and non-coding micro RNA (miRNA) expression [201-203]. $\mathrm{Cd}$ has been shown to interfere with the epigenetic regulation of gene expression by inducing DNMT deregulation, global DNA methylation changes, locus-specific DNA hypomethylation or hypermethylation, together with histone modifications and miRNAs level fluctuations, in several tissues and cell lines, as well as in human studies. These Cd-induced epigenetics events, however, mainly result in overt neoplastic transformation [165-169]; nevertheless, the epigenetic effects of Cd implicated in male fertility are poorly characterized. DNA methylation is involved in the proper functioning of spermatozoa genome and exerts crucial effects on spermatozoa function [204]. A complex and precise epigenetic reprogramming takes place in germ cells, and is essential for spermatogenesis; this process consists of a global demethylation-remethylation program which allows the removal of a somatic-like pattern of DNA methylation, and the acquisition of a gender-specific pattern, by de novo methylation [204]. An improperly elevated global (LINE-1 repetitive elements, a proxy marker of global DNA) and locusspecific (at imprinted and non-imprinted genes) methylation was demonstrated in poor quality human semen samples [205,206]; moreover, genome-wide and locus-specific (H19, MEST, BRDT, MTHFR) alterations of methylation patterns were associated to an impairment of semen quality or azoospermia, in human subjects [206-214].

Time-dependent differential epigenetic effects were reported after $\mathrm{Cd}$ exposure, in in vitro and ex vivo models. In vitro studies on rat liver cells, and ex vivo DNMT assays, showed that acute $\mathrm{Cd}$ exposure and exposure for 1 week were associated to decreased DNMT activity, and subsequent global DNA hypomethylation [215]; by contrast, longer chronic Cd exposure for 10 weeks was shown to increase DNMT activity, therefore stimulating global DNA hypermethylation [215]. Consistently, neonatal Cd exposure of rats for 5 days resulted in decreased DNMT activity [216], and global DNA hypomethylation, in the testis [217]. Moreover, in TM3 mouse Leydig cell line, $72 \mathrm{~h}$ of treatment with $\mathrm{Cd}$ induced a dose dependent decrease in DNMT1 expression [218]. In humans, in a study evaluating the association between placental $\mathrm{Cd}$ and placental DNA methylation, it was shown that, in male newborns, high placental Cd was correlated to locus-specific alterations of DNA methylation of genes involved in cell differentiation, angiogenesis, and organ development [219]. An epidemiological study on an adult population exposed to high environmental Cd concentrations, evaluated the association between DNA methylation (assessed in whole blood DNA) and Cd exposure, by taking into account gender and smoking habits [220]. In this study, uCd was positively correlated to global DNA hypermethylation, as measured as LINE-1 methylation status, in men; when adjusting results for smoking habits, this correlation was maintained [220]. Similar results were also described in male newborns prenatally exposed to Cd [221]. As previously discussed, LINE-1 hypermethylation has been associated to impaired semen quality, in particular, to an impairment of total motility and progressive forward motility, in humans [206]; nevertheless, to the best of our knowledge, no studies directly evaluated the epigenetic signature in Cd-exposed versus non-exposed male subjects, nor directly correlated this feature to semen quality and fertility. Moreover, the locus-specific epigenetic effects of $\mathrm{Cd}$ have not been investigated in fertility-related genes, in Cd exposed versus non-exposed subjects. Lastly, important considerations should be made, when analyzing epigenetic studies, since dose-, time-, species- and tissue-specific differences in epigenetic modifications may occur, after exposure to the same compound; therefore, well- designed studies correlating $\mathrm{Cd}$-induced epigenetic changes to semen quality and male 
infertility should include global and locus-specific DNA analysis in the pertinent tissue, in order to precisely define the tissuespecific epigenetic profile following Cd exposure. In summary, the results of these studies suggest that the interference with epigenetic gene regulation, which is mainly proven to be implicated in neoplastic transformation, may potentially mediate the toxic effect of $\mathrm{Cd}$ on semen quality, although dedicated studies are lacking and further verification is required to strenghten this hypothesis.

\subsection{Disruption of hypothalamus-pituitary-gonadal axis}

Experimental in vitro and in vivo studies in animals and experimental in vitro studies on human cultured cells, suggest that Cd may exert its reprotoxicity not only by a direct injury on target organs and cells, but also by indirectly disturbing the hypothalamuspituitary-gonadal axis [222]. A large number of studies documented that $\mathrm{Cd}$ mimics the function of steroid hormones; therefore, this "metallohormone" has been proposed as endocrine disruptor interfering with endogenous endocrine system. It has been shown that $\mathrm{Cd}$ can directly bind to estrogen receptor and androgen receptor, and that $\mathrm{Cd}$ exerts strong estrogenic-like and androgeniclike actions, both in vivo and in vitro. Estrogenic effects of $\mathrm{Cd}$ are mediated by the high affinity binding to the ligand-binding domain of estrogen receptor $\alpha$ [223], the receptor isoform that drives the mitogenic actions of $E_{2}$ in target organs. $C d$ has been shown to induce proliferation, and to promote the expression of estrogen-induced genes, in in vitro cultures of human breast cancer cells [224,225]. Moreover, Cd was demonstrated to activate the non-genomic estrogen receptor $\alpha$ pathway, through extracellular regulated kinase $1 / 2$ and protein kinase $B$, in breast cancer cells $[225,226]$. In vivo studies on animal models reported that low doses of $\mathrm{Cd}$ mimic the effects of estrogen in target organs, such as the mammary gland and uterus [227]. Androgenic effects of Cd are mediated by the high affinity binding to the ligand-binding domain of androgen receptor, and subsequent activation of downstream signaling. $\mathrm{Cd}$ has been shown to prevent androgens from binding to their receptor, and to mimic the actions of androgens on cell growth and gene expression in vitro [228]. Moreover, in vivo studies in castrated rats demonstrated that low doses of Cd dose-dependently increased the weight of the prostate gland and of the seminal vesicles; this effect was blocked by an antiandrogen, by supporting the evidence that Cd actions are driven by androgen receptor [228]. In addition, in intact animals, Cd significantly increased the weight of the prostate gland and of the seminal vesicles, and this outcome was not reversed upon castration, by confirming that $\mathrm{Cd}$ induces the hypertrophy of these organs by activating the androgen receptor, and that $\mathrm{T}$ deprivation is not sufficient to reverse this effect [229]. As previously discussed, Cd significantly affects the endocrine system, and causes hormonal imbalance by altering the effective concentrations of gonadotropins, $\mathrm{T}$ [55,77-79] , and INH-B [75], in experimental models. It was also shown that, in the testis of mice and rats, Cd affects the expression of steroidogenesis enzymes, such as StAR, cholesterol C20-22 desmolase, $17 \alpha$-hydroxylase, $17 \beta$-hydroxysteroid dehydrogenase [48], and suppresses the expression of LH receptor [230]. All of these effects on the endocrine system are driven not only by direct effects on target organs and cells, but also by an impairment of the circadian release of noradrenaline, with subsequent changes in gonadotropin-releasing hormone secretion from the hypothalamus, in LH and prolactin secretion from the pituitary, and in $\mathrm{T}$ circulating concentrations, in male rats $[55,231,232]$. In summary, the results of these studies suggest that disruption of the hypothalamus-pituitary-gonadal axis may mediate the toxic effect of $\mathrm{Cd}$ on spermatogenesis and testis endocrine function.

\section{Sensitivity and resistance to cadmium reprotoxicity}

Toxicity is a phenomenon determined by alterations in the balance between sensitivity and resistance of a given target to a specific detrimental stimulus, resulting in structural or functional damage, when protective factors are insufficient to neutralize the action of the toxic stimuli. Despite the extensive evidences on the specific mechanisms driving Cd-induced reprotoxicity, less information is available on the specific mechanisms, which dictate the susceptibility of testis to $\mathrm{Cd}$-induced damage. Moreover, the factors regulating the balance between sensitivity and resistance to $\mathrm{Cd}$ in the testis have not been completely addressed, although experimental in vitro and in vivo studies in animals highlighted that, in the testis, specific factors might regulate $C d$ sensitivity and resistance. Most of Cd accumulated in the body is bound to metallothioneins (MTs), low-molecular-weight, cysteine-rich, metal-binding proteins [233]. MTs function as a storage for Zn, and are free-radical scavengers. These proteins are induced by both physiologic and toxic stimuli, including $\mathrm{Cd}$ and different metal ions, and represent a defense machinery against $\mathrm{Cd}$ toxicity. MTs are in charge of the retention of $\mathrm{Cd}$ in various tissues, by sequestering the metal into the cytosol, and by reducing its bioavailability for intracellular organelles [234]. It was shown that the exposure of animals to low doses of $\mathrm{Cd}$ exerts a protective effect toward further acute $\mathrm{Cd}$ intoxication, by markedly inducing the expression of MTs [235]. The role of MTs in binding and sequestering Cd in the testis is unclear and controversial. In vivo studies in animals showed that treatment with low doses of $\mathrm{Cd}(0.2$ and $0.4 \mathrm{mg} / \mathrm{kg}$ body weight $)$ mildly induced MTs in the testis, whereas higher doses $(0.8 \mathrm{mg} / \mathrm{kg}$ body weight) of Cd markedly reduced MTs expression [236,237]; nevertheless, after treatment with Cd, the levels of MTs in the testis raised much less than in the liver, suggesting that, in the testis, MTs are less inducible by $\mathrm{Cd}$ exposure, compared to different organs, and could be responsible for the higher sensitivity of testis to $\mathrm{Cd}$ poisoning [236,237]. However, microarray analysis of Cd-exposed testis from Cd-sensitive, Cd-resistant and MTs-null mice, demonstrated that MTs play no significant role in the protection of the testis against acute $\mathrm{Cd}$ intoxication, and that it is the genetic background which determines sensitivity to Cd [238]. ZIP8 transporter might be involved in the sensitivity to Cd toxicity; indeed, experiments in vitro demonstrated that ZIP8 messenger and protein levels were reduced in Cd-resistant MTs-null embryonic fibroblasts, by leading to a decrease in Cd accumulation [239]. Additionally, the experimental induction of ZIP8 expression in these cells determined $\mathrm{Cd}$ intracellular accumulation, and increased the sensitivity to Cd [239]. ZIP8 messenger level was found to be highly prominent in the vascular endothelial cells of the testis of Cd-sensitive strains, but absent in Cd-resistant strains of mice [64]. In summary, although little information is available on the precise mechanisms regulating the balance between sensitivity and resistance to $\mathrm{Cd}$ reprotoxicity, it has been suggested that MTs might contribute to the protection against $\mathrm{Cd}$-induced testis toxicity, whereas a much relevant role seems to be exerted by the genetic background, and, in particular, by the expression of ZIP8 transporters in the testis.

\section{Conclusions}

The experimental results from animal and human studies presented by the current review strongly corroborate the reprotoxicity of $\mathrm{Cd}$, either at high or even at low experimental doses; neverthless, epidemiological observational findings in humans are quite controversial, due to a high heterogeneity of study designs, and to the challenging selection of study populations. In order to establish a precise dose-response relationship and a safety threshold of Cd exposure, subjects stratification should take into account 
the different patterns of $\mathrm{Cd}$ exposure (chemical form, route, dose, and duration of exposure), the influence of different risk factors affecting $\mathrm{Cd}$ concentration, or further compromise the reproductive function, as well as the possible multiple exposure to different metals and pollutants, and the interaction between deleterious and protective compounds. Studies should also be corrected for potential confounders and covariates, such as age, general health status, dietary habits, use of medications and supplements, tobacco smoking, and alcohol consumption. Lastly, experimental studies in humans are lacking, except for two in vitro studies on spermatozoa, which seems to support a detrimental effect of $\mathrm{Cd}$ on spermatozoa metabolism and semen quality. Conversely, compelling evidences from experimental in vitro, ex vivo and in vivo studies in animal models, strongly support the hypothesis that $\mathrm{Cd}$ affects male reproductive function, including spermatogenesis and semen quality, as well as endocrine function, at multiple levels, depending on $\mathrm{Cd}$ concentration and duration of exposure. Indeed, Cd induces severe structural damage to testis vascular endothelium, which ultimately results in necrosis of the testis, and impaired spermatogenesis and testis endocrine function, and affects the BTB integrity, which might lead to susceptibility to toxicity and to the development of autoimmunity against germ cells, although this hypothesis has not been further investigated. Moreover, Cd might affect spermatogenesis, semen quality and testis endocrine function by inducing inflammation and apoptosis within the testis, by means of direct effects on inflammation mediators, and on pro-apoptotic and anti-apoptotic factors, and by interference with selected signaling pathways involved in the regulation of the reproductive function, such as UPS, calcium, and cyclic AMP. In addition, Cd exerts targeted effects on selected cell populations of the testis, which include direct cytotoxicity and functional impairment of Sertoli and Leydig cells, and oxidative stress in both somatic and germ cells, mainly by means of mimicry mechanisms and interference with essential ions involved in antioxidative activity, beyond apoptosis occurring in germ cells. Moreover, $\mathrm{Cd}$ induces epigenetic modifications in Leydig cells and testis of Cdtreated animals, which might potentially determine an impairment of semen quality, although these changes were not directly linked to reproductive dysfunction. Lastly, Cd treatment determines a direct disturbance of the hypothalamus-pituitary-gonadal axis, which might determine the impairment of spermatogenesis and endocrine function. Animal studies significantly contributed to the identification of $\mathrm{Cd}$ targets, and to the characterization of the pathogenetic mechanisms underlying Cd reprotoxicity; nevertheless, conceivable differences in the susceptibility to adverse reproductive effects between humans and mammalian animals must be addressed. Moreover, the exact correspondence between realistic human exposure levels and the experimental doses employed in animal studies remains to be fully established. Additional welldesigned observational studies, as well as further experimental research in humans, are required to eliminate inconsistencies, and to confirm the effects of $\mathrm{Cd}$ on human male reproductive function; a tight collaboration between epidemiologists, clinicians, geneticists, and molecular biologists, would be highly suited to achieve these challenging goals.

\section{Conflict of interests}

All authors declare no conflict of interests concerning this paper.

\section{Authors' contributions}

CdA conceived and developed the manuscript, performed the literature search, wrote the manuscript, conceived and prepared tables and figures. MG substantially contributed to the writing of the epidemiological section and the preparation of tables. CP contributed to manuscript preparation. CS contributed to the preparation of tables and figures. DG provided a significant expert contribution in the scientific content revision process. PP contributed to manuscript drafting, and helped to revise the final version. AL critically revised the manuscript. AC critically revised the manuscript. RP is the principal investigator, significantly contributed to conceive and supervised the manuscript drafting, and critically reviewed and revised the manuscript relavantly improving the scientific content and the formal style. All authors read and approved the final manuscript.

\section{Acknowledgement}

Authors are thankful to Prof. Loredana Gandini for the significant contribution provided to the expert revision of the scientific content of the manuscript. Authors wish to devote this manuscript to her memory.

\section{References}

[1] WorldBank, Fertility Rates, 2015 http://data.worldbank.org/indicator/SP DYN.TFRT.IN.

[2] E. Carlsen, A. Giwercman, N. Keiding, N.E. Skakkebaek, Evidence for decreasing quality of semen during past 50 years, BMJ 305 (6854) (1992) 609-613.

[3] H. Fisch, S.R. Braun, Trends in global semen parameter values, Asian J. Androl. 15 (2) (2013) 169-173.

[4] L. Nordkap, U.N. Joensen, M.B. Jensen, N. Jorgensen, Regional differences and temporal trends in male reproductive health disorders: semen quality may be a sensitive marker of environmental exposures, Mol. Cell. Endocrinol. 355 (2) (2012) 221-230

[5] J. Knez, Endocrine-disrupting chemicals and male reproductive health, Reprod. Biomed. Online 26 (5) (2013) 440-448.

[6] P. Jenardhanan, M. Panneerselvam, P.P. Mathur, Effect of environmental contaminants on spermatogenesis, Semin. Cell Dev. Biol. 59 (November) (2016) 126-140

[7] ATSDR, Toxicological profile forcadmium 2012, in: Toxicological Profiles, Agency for Toxic Substances and Disease Registry, 2012.

[8] IARC, IARC monographs vol. 100C, in: Evaluation of Carcinogenic Risks to Humans, International Agency for Research on Cancer Lyon, France, 2012.

[9] B. Tariba, Metals in wine-impact on wine quality and health outcomes, Biol. Trace Elem. Res. 144 (1-3) (2011) 143-156.

[10] IARC, IARC monographs vol. 58, in: Evaluation of Carcinogenic Risks to Humans, International Agency for Research on Cancer Lyon, France, 1993.

[11] M. Vahter, M. Berglund, A. Akesson, C. Liden, Metals and women's health, Environ. Res. 88 (3) (2002) 145-155.

[12] M. Vahter, A. Akesson, C. Liden, S. Ceccatelli, M. Berglund, Gender differences in the disposition and toxicity of metals, Environ. Res. 104 (1) (2007) 85-95.

[13] M. Berglund, A. Akesson, B. Nermell, M. Vahter, Intestinal absorption of dietary cadmium in women depends on body iron stores and fiber intake, Environ. Health Perspect. 102 (12) (1994) 1058-1066.

[14] M.M. Brzoska, J. Moniuszko-Jakoniuk, Interactions between cadmium and zinc in the organism, Food Chem. Toxicol. 39 (10) (2001) 967-980.

[15] S. Telisman, Interactions of essential and/or toxic metals and metalloid regarding interindividual differences in susceptibility to various toxicants and chronic diseases in man, Arh. Hig. Rada Toksikol. 46 (4) (1995) 459-476.

[16] G.F. Nordberg, Historical perspectives on cadmium toxicology, Toxicol. Appl. Pharmacol. 238 (3) (2009) 192-200

[17] O. Akinloye, A.O. Arowojolu, O.B. Shittu, J.I. Anetor, Cadmium toxicity: a possible cause of male infertility in Nigeria, Reprod. Biol. 6 (1) (2006) 17-30.

[18] B. Varga, B. Zsolnai, K. Paksy, M. Naray, G. Ungvary, Age dependent accumulation of cadmium in the human ovary, Reprod. Toxicol. 7 (3) (1993) 225-228

[19] A.M. Ronco, G. Arguello, L. Munoz, N. Gras, M. Llanos, Metals content in placentas from moderate cigarette consumers: correlation with newborn birth weight, Biomet. Int. J. Role Met. Ions Biol. Biochem. Med. 18 (3) (2005) 233-241.

[20] B.R. Danielsson, L. Dencker, A. Lindgren, H. Tjalve, Accumulation of toxic metals in male reproduction organs, Arch. Toxicol. Suppl.=Archiv fur Toxikologie Supplement 7 (1984) 177-180.

[21] R. Swiergosz-Kowalewska, Cadmium distribution and toxicity in tissues of small rodents, Microsc. Res. Tech. 55 (3) (2001) 208-222.

[22] J. Mendiola, J.M. Moreno, M. Roca, N. Vergara-Juarez, M.J. Martinez- Garcia, A. Garcia-Sanchez, B. Elvira-Rendueles, S. Moreno-Grau, J.J. Lopez-Espin, J. Ten, R. Bernabeu, A.M. Torres-Cantero, Relationships between heavy metal concentrations in three different body fluids and male reproductive 
parameters: a pilot study, Environ. Health: Global Access Sci. Source 10 (1) (2011) 6.

[23] L. Minguez-Alarcon, J. Mendiola, M. Roca, J.J. Lopez-Espin, J.J. Guillen, J.M. Moreno, S. Moreno-Grau, M.J. Martinez-Garcia, N. Vergara-Juarez, B. ElviraRendueles, A. Garcia-Sanchez, J. Ten, R. Bernabeu, A.M. Torres-Cantero, Correlations between different heavy metals in diverse body fluids: studies of human semen quality, Adv. Urol. 2012 (2012) 420893.

[24] S.E. Chia, B. Xu, C.N. Ong, F.M. Tsakok, S.T. Lee, Effect of cadmium and cigarette smoking on human semen quality, Int. J. Fertil. Menopausal. Stud. 39 (5) (1994) 292-298.

[25] S. Telisman, J. Jurasovic, A. Pizent, P. Cvitkovic, Cadmium in the blood and seminal fluid of nonoccupationally exposed adult male subjects with regard to smoking habits, Int. Arch. Occup. Environ. Health 70 (4) (1997) 243-248.

[26] R. Sharma, A. Harlev, A. Agarwal, S.C. Esteves, Cigarette smoking and semen quality a new meta-analysis examining the effect ofthe 2010 world health organization laboratory methods for the examination of human semen, Eur. Urol. 70 (4) (2016) 635-645.

[27] S. Benoff, R. Hauser, J.L. Marmar, I.R. Hurley, B. Napolitano, G.M. Centola, Cadmium concentrations in blood and seminal plasma: correlations with sperm number and motility in three male populations (infertility patients, artificial insemination donors, and unselected volunteers), Mol. Med. 15 (7-8) (2009) 248-262.

[28] N. Pant, G. Kumar, A.D. Upadhyay, Y.K. Gupta, P.K. Chaturvedi, Correlation Between Lead and Cadmium Concentration and Semen Quality, Andrologia, 2014.

[29] S.E. Chia, C.N. Ong, S.T. Lee, F.H. Tsakok, Blood concentrations of lead, cadmium, mercury, zinc, and copper and human semen parameters, Arch. Androl. 29 (2) (1992) 177-183.

[30] B. Xu, S.E. Chia, M. Tsakok, C.N. Ong, Trace elements in blood and seminal plasma and their relationship to sperm quality, Reprod. Toxicol. 7 (6) (1993) 613-618.

[31] W. Guzikowski, M.I. Szynkowska, H. Motak-Pochrzest, A. Pawlaczyk, S. Sypniewski, Trace elements in seminal plasma of men from infertile couples, Arch. Med. Sci. AMS 11 (3) (2015) 591-598.

[32] S. Telisman, P. Cvitkovic, J. Jurasovic, A. Pizent, M. Gavella, B. Rocic, Semen quality and reproductive endocrine function in relation to biomarkers of lead, cadmium, zinc, and copper in men, Environ. Health Perspect. 108 (1) (2000) 45-53.

[33] J. Slivkova, M. Popelkova, P. Massanyi, S. Toporcerova, R. Stawarz, G. Formicki, N. Lukac, A. Putala, M. Guzik, Concentration of trace elements in human semen and relation to spermatozoa quality, J. Environ. Sci. Health Part A Tox. Hazard. Subst. Environ. Eng. 44 (4) (2009) 370-375.

[34] D.X. Xu, H.M. Shen, Q.X. Zhu, L. Chua, Q.N. Wang, S.E. Chia, C.N. Ong, The associations among semen quality, oxidative DNA damage in human spermatozoa and concentrations of cadmium, lead and selenium in seminal plasma, Mutat. Res. 534 (1-2) (2003) 155-163.

[35] A.R. Kiziler, B. Aydemir, I. Onaran, B. Alici, H. Ozkara, T. Gulyasar, M.C. Akyolcu, High levels of cadmium and lead in seminal fluid and blood of smoking men are associated with high oxidative stress and damage in infertile subjects, Biol. Trace Elem. Res. 120 (1-3) (2007) 82-91.

[36] E.B. Dawson, S. Ritter, W.A. Harris, D.R. Evans, L.C. Powell, Comparison of sperm viability with seminal plasma metal levels, Biol. Trace Elem. Res. 64 (1-3) (1998) 215-219.

[37] J.D. Meeker, M.G. Rossano, B. Protas, M.P. Diamond, E. Puscheck, D. Daly, N. Paneth, J.J. Wirth, Cadmium, lead, and other metals in relation to semen quality: human evidence for molybdenum as a male reproductive toxicant Environ. Health Perspect. 116 (11) (2008) 1473-1479.

[38] J. Jurasovic, P. Cvitkovic, A. Pizent, B. Colak, S. Telisman, Semen quality and reproductive endocrine function with regard to blood cadmium in Croatian male subjects, Biomet. Int. J. Role Met. Ions Biol. Biochem. Med. 17 (6) (2004) 735-743.

[39] C. Keck, G. Bramkamp, H.M. Behre, C. Muller, F. Jockenhovel, E. Nieschlag, Lack of correlation between cadmium in seminal plasma and fertility status of nonexposed individuals and two cadmium- exposed patients, Reprod. Toxicol. 9 (1) (1995) 35-40.

[40] M. Saaranen, M. Kantola, S. Saarikoski, T. Vanha- Perttula, Human seminal plasma cadmium: comparison with fertility and smoking habits, Andrologia 21 (2) (1989) 140-145.

[41] J.D. Meeker, M.G. Rossano, B. Protas, V. Padmanahban, M.P. Diamond, E. Puscheck, D. Daly, N. Paneth, J.J. Wirth, Environmental exposure to metals and male reproductive hormones: circulating testosterone is inversely associated with blood molybdenum, Fertil. Steril. 93 (1) (2010) 130-140.

[42] X. Zeng, T. Jin, J.P. Buchet, X. Jiang, Q. Kong, T. Ye, A. Bernard, G.F. Nordberg, Impact of cadmium exposure on male sex hormones: a population-based study in China, Environ. Res. 96 (3) (2004) 338-344.

[43] O. Hovatta, E.R. Venalainen, L. Kuusimaki, J. Heikkila, T. Hirvi, I. Reima, Aluminium, lead and cadmium concentrations in seminal plasma and spermatozoa, and semen quality in Finnish men, Hum. Reprod. 13 (1) (1998) $115-119$.

[44] X. Zeng, T. Lin, Y. Zhou, Q. Kong, Alterations of serum hormone levels in male workers occupationally exposed to cadmium, J. Toxicol. Environ. Health A 65 (7) (2002) 513-521.

[45] N. Pant, A.B. Pant, P.K. Chaturvedi, M. Shukla, N. Mathur, Y.K. Gupta, D.K. Saxena, Semen quality of environmentally exposed human population: the toxicological consequence, Environ. Sci. Pollut. Res. Int. 20 (11) (2013) 8274-8281.
[46] U. Kanwar, S. Chadha, A. Batla, S.N. Sanyal, R. Sandhu, Effect of selected metal ions on the motility and carbohydrate metabolism of ejaculated human spermatozoa, Indian J. Physiol. Pharmacol. 32 (3) (1988) 195-201.

[47] R.M. Sharpe, C. McKinnell, C. Kivlin, J.S. Fisher, Proliferation and functional maturation of Sertoli cells, and their relevance to disorders of testis function in adulthood, Reproduction 125 (6) (2003) 769-784.

[48] Y.L. Ji, H. Wang, P. Liu, X.F. Zhao, Y. Zhang, Q. Wang, H. Zhang, C. Zhang, Z.H. Duan, C. Meng, D.X. Xu, Effects of maternal cadmium exposure during late pregnant period on testicular steroidogenesis in male offspring, Toxicol. Lett. 205 (1) (2011) 69-78

[49] P.P. Tam, W.K. Liu, Gonadal development and fertility of mice treated prenatally with cadmium during the early organogenesis stages, Teratology 32 (3) (1985) 453-462.

[50] L.C. Xu, S.Y. Wang, X.F. Yang, X.R. Wang, Effects of cadmium on rat sperm motility evaluated with computer assisted sperm analysis, Biomed. Environ Sci. BES 14 (4) (2001) 312-317.

[51] K.W. Hew, W.A. Ericson, M.J. Welsh, A single low cadmium dose causes failure of spermiation in the rat, Toxicol. Appl. Pharmacol. 121 (1) (1993) $15-21$.

[52] F.M. El-Demerdash, M.I. Yousef, F.S. Kedwany, H.H. Baghdadi, Cadmium-induced changes in lipid peroxidation, blood hematology, biochemical parameters and semen quality of male rats: protective role of vitamin E and beta-carotene, Food Chem. Toxicol. 42 (10) (2004) 1563-1571.

[53] S.K. Saksena, I.F. Lau, Effects of cadmium chloride on testicular steroidogenesis and fertility of male rats, Endokrinologie 74 (1) (1979) 6-12.

[54] J.W. Laskey, G.L. Rehnberg, S.C. Laws, J.F. Hein, Reproductive effects of low acute doses of cadmium chloride in adult male rats, Toxicol. Appl. Pharmacol. 73 (2) (1984) 250-255.

[55] A. Lafuente, A. Gonzalez-Carracedo, A. Romero, P. Cano, A.I. Esquifino, Cadmium exposure differentially modifies the circadian patterns of norepinephrine at the median eminence and plasma LH, FSH and testosterone levels, Toxicol. Lett. 146 (2) (2004) 175-182.

[56] S. Benoff, K. Auborn, J.L. Marmar, I.R. Hurley, Link between low-dose environmentally relevant cadmium exposures and asthenozoospermia in a rat model, Fertil. Steril. 89 (Suppl 2) (2008) e73-e79.

[57] S. Saygi, G. Deniz, O. Kutsal, N. Vural, Chronic effects of cadmium on kidney, liver, testis, and fertility of male rats, Biol. Trace Elem. Res. 31 (3) (1991) 209-214.

[58] M. Monsefi, S. Alaee, A. Moradshahi, L. Rohani, Cadmium-induced infertility in male mice, Environ. Toxicol. 25 (1) (2010) 94-102.

[59] S.A. Gunn, T.C. Gould, W.A. Anderson, The selective injurious response of testicular and epididymal blood vessels to cadmium and its prevention by zinc, Am. J. Pathol. 42 (1963) 685-702.

[60] B.P. Setchell, G.M. Waites, Changes in the permeability of the testicular capillaries and of the 'blood-testis barrier' after injection of cadmium chloride in the rat, J. Endocrinol. 47 (1) (1970) 81-86.

[61] A. Aoki, A.P. Hoffer, Reexamination of the lesions in rat testis caused by cadmium, Biol. Reprod. 18 (4) (1978) 579-591.

[62] W.C. Prozialeck, J.R. Edwards, D.W. Nebert, J.M. Woods, A. Barchowsky, W.D Atchison, The vascular system as a target of metal toxicity, Toxicol. Sci. 102 (2) (2008) 207-218.

[63] W.C. Prozialeck, J.R. Edwards, J.M. Woods, The vascular endothelium as a target of cadmium toxicity, Life Sci. 79 (16) (2006) 1493-1506.

[64] T.P. Dalton, L. He, B. Wang, M.L. Miller, L. Jin, K.F. Stringer, X. Chang, C.S. Baxter, D.W. Nebert, Identification of mouse SLC39A8 as the transporter responsible for cadmium-induced toxicity in the testis, Proc. Natl. Acad. Sci. U. S. A. 102 (9) (2005) 3401-3406.

[65] C.Y. Cheng, D.D. Mruk, The blood-testis barrier and its implications for male contraception, Pharmacol. Rev. 64 (1) (2012) 16-64.

[66] N.P. Chung, C.Y. Cheng, Is cadmium chloride-induced inter-sertoli tight junction permeability barrier disruption a suitable in vitro model to study the events of junction disassembly during spermatogenesis in the rat testis? Endocrinology 142 (5) (2001) 1878-1888.

[67] E.R. Siu, D.D. Mruk, C.S. Porto, C.Y. Cheng, Cadmium-induced testicular injury, Toxicol. Appl. Pharmacol. 238 (3) (2009) 240-249.

[68] E.R. Siu, E.W. Wong, D.D. Mruk, K.L. Sze, C.S. Porto, C.Y. Cheng, An occludin-focal adhesion kinase protein complex at the blood-testis barrier: a study using the cadmium model, Endocrinology 150 (7) (2009) 3336-3344.

[69] W.Y. Lui, C.H. Wong, D.D. Mruk, C.Y. Cheng, TGF-beta3 regulates the blood-testis barrier dynamics via the p38 mitogen activated protein (MAP) kinase pathway: an in vivo study, Endocrinology 144 (4) (2003) 1139-1142.

[70] A.A. Fouad, W.H. Albuali, I. Jresat, Simvastatin treatment ameliorates injury of rat testes induced by cadmium toxicity, Biol. Trace Elem. Res. $153(1-3)$ (2013) 269-278

[71] S.M. Eleawa, M.A. Alkhateeb, F.H. Alhashem, I. Bin- Jaliah, H.F. Sakr, H.M Elrefaey, A.O. Elkarib, R.M. Alessa, M.A. Haidara, A.S. Shatoor, M.A. Khalil, Resveratrol reverses cadmium chloride-induced testicular damage and subfertility by downregulating p53 and Bax and upregulating gonadotropins and Bcl-2 gene expression, J. Reprod. Dev. 60 (2) (2014) 115-127.

[72] T. Bu, Y. Mi, W. Zeng, C. Zhang, Protective effect of quercetin on cadmium-induced oxidative toxicity on germ cells in male mice, Anat. Rec. 294 (3) (2011) 520-526.

[73] Y.L. Ji, H. Wang, X.F. Zhao, Q. Wang, C. Zhang, Y. Zhang, M. Zhao, Y.H. Chen, X.H. Meng, D.X. Xu, Crosstalk between endoplasmic reticulum stress and mitochondrial pathway mediates cadmium-induced germ cell apoptosis in testes, Toxicol. Sci. 124 (2) (2011) 446-459. 
[74] S.R. Clough, M.J. Welsh, A.H. Payne, C.D. Brown, M.J. Brabec, Primary rat Sertoli and interstitial cells exhibit a differential response to cadmium, Cell Biol. Toxicol. 6 (1) (1990) 63-79.

[75] G. Luca, C. Lilli, C. Bellucci, F. Mancuso, M. Calvitti, I. Arato, G. Falabella, S. Giovagnoli, M.C. Aglietti, A. Lumare, G. Muzi, R. Calafiore, M. Bodo, Toxicity of cadmium on Sertoli cell functional competence: an in vitro study, J. Biol. Regul. Homeost. Agents 27 (3) (2013) 805-816.

[76] T.B. Ng, W.K. Liu, Toxic effect of heavy metals on cells isolated from the rat adrenal and testis, In vitro Cell. Dev. Biol.: J. Tissue Cult. Assoc. 26 (1) (1990) 24-28.

[77] J.M. Yang, M. Arnush, Q.Y. Chen, X.D. Wu, B. Pang, X.Z. Jiang, Cadmium-induced damage to primary cultures of rat Leydig cells, Reprod. Toxicol. 17 (5) (2003) 553-560.

[78] J.W. Laskey, P.V. Phelps, Effect of cadmium and other metal cations on in vitro Leydig cell testosterone production, Toxicol. Appl. Pharmacol. 108 (2) (1991) 296-306.

[79] P.V. Phelps, J.W. Laskey, Comparison of age-related changes in vivo and in vitro measures of testicular steroidogenesis after acute cadmium exposure in the Sprague-Dawley rat, J. Toxicol. Environ. Health 27 (1) (1989) 95-105.

[80] C.C. Bridges, R.K. Zalups, Molecular and ionic mimicry and the transport of toxic metals, Toxicol. Appl. Pharmacol. 204 (3) (2005) 274-308.

[81] B.L. Vallee, K.H. Falchuk, The biochemical basis of zinc physiology, Physiol. Rev. 73 (1) (1993) 79-118.

[82] A.E. Favier, The role of zinc in reproduction. Hormonal mechanisms, Biol. Trace Elem. Res. 32 (1992) 363-382.

[83] I.M. Ebisch, C.M. Thomas, W.H. Peters, D.D. Braat, R.P. Steegers-Theunissen, The importance of folate, zinc and antioxidants in the pathogenesis and prevention of subfertility, Hum. Reprod. Update 13 (2) (2007) $163-174$.

[84] R. Walczak-Jedrzejowska, J.K. Wolski, J. Slowikowska- Hilczer, The role of oxidative stress and antioxidants in male fertility, Cent. Eur. J. Urol. 66 (1) (2013) 60-67.

[85] D.S. Auld, Zinc coordination sphere in biochemical zinc sites, Biomet. Int. J. Role Met. Ions Biol. Biochem. Med. 14 (3-4) (2001) 271-313.

[86] R.K. Zalups, S. Ahmad, Molecular handling of cadmium in transporting epithelia, Toxicol. Appl. Pharmacol. 186 (3) (2003) 163-188.

[87] I. Aiba, A. Hossain, M.T. Kuo, Elevated GSH level increases cadmium resistance through down-regulation of Sp1-dependent expression of the cadmium transporter ZIP8, Mol. Pharmacol. 74 (3) (2008) 823-833.

[88] K. Girijashanker, L. He, M. Soleimani, J.M. Reed, H. Li, Z. Liu, B. Wang, T.P. Dalton, D.W. Nebert, Slc39a14 gene encodes ZIP14, a metal/bicarbonate symporter: similarities to the ZIP8 transporter, Mol. Pharmacol. 73 (5) (2008) 1413-1423.

[89] L.M. King, W.A. Banks, W.J. George, Differences in cadmium transport to the testis, epididymis, and brain in cadmium-sensitive and -resistant murine strains 129/J and A/J, J. Pharmacol. Exp. Ther. 289 (2) (1999) 825-830.

[90] Z. Liu, H. Li, M. Soleimani, K. Girijashanker, J.M. Reed, L. He, T.P. Dalton, D.W Nebert, Cd2+ versus Zn2+ uptake by the ZIP8 HCO3-dependent symporter: kinetics, electrogenicity and trafficking, Biochem. Biophys. Res. Commun. 365 (4) (2008) 814-820.

[91] M.P. Waalkes, L.A. Poirier, Interactions of cadmium with interstitial tissue of the rat testes. Uptake of cadmium by isolated interstitial cells, Biochem. Pharmacol. 34 (14) (1985) 2513-2518.

[92] R.J. McMahon, R.J. Cousins, Mammalian zinc transporters, J. Nutr. 128 (4) (1998) 667-670.

[93] V. Matovic, A. Buha, Z. Bulat, D. Dukic-Cosic, Cadmium toxicity revisited: focus on oxidative stress induction and interactions with zinc and magnesium, Arh. Hig. Rada Toksikol. 62 (1) (2011) 65-76.

[94] D.E. Coppen-Jaeger, M. Wilhelm, The effects of cadmium on zinc absorption in isolated rat intestinal preparations, Biol. Trace Elem. Res. 21 (1989) 207-212.

[95] A. Pizent, J. Jurasovic, S. Telisman, Serum calcium, zinc, and copper in relation to biomarkers of lead and cadmium in men, J. Trace Ele. Med. Biol. Organ Soc. Miner. Trace Ele. 17 (3) (2003) 199-205

[96] M.R. Fox, S.H. Tao, C.L. Stone, B.E. Fry Jr., Effects of zinc, iron and copper deficiencies on cadmium in tissues of Japanese quail, Environ. Health Perspect. 54 (1984) 57-65

[97] A. Al-Bader, A.E. Omu, H. Dashti, Chronic cadmium toxicity to sperm of heavy cigarette smokers: immunomodulation by zinc, Arch. Androl. 43 (2) (1999) 135-140.

[98] V. Matoviæ, Z. Plamenac-Bulat, D. Djukiæ-Æosiæ, S. D, Zinc, Copper or Magnesium Supplementation Against Cadmium Toxicity: an Experimental Study, Nova Science Publisher, New York, 2010.

[99] Z.P. Bulat, D. Djukic-Cosic, Z. Malicevic, P. Bulat, V. Matovic, Zinc or magnesium supplementation modulates cd intoxication in blood, kidney, spleen, and bone of rabbits, Biol. Trace Elem. Res. 124 (2) (2008) 110-117.

[100] K.B. Jacobson, J.E. Turner, The interaction of cadmium and certain other metal ions with proteins and nucleic acids, Toxicology 16 (1) (1980) 1-37.

[101] S. Saksena, M.J. White, J. Mertzlufft, I. Lau, Prevention of cadmium-induced sterility by zinc in the male rat, Contraception 27 (5) (1983) 521-530.

[102] D. Burukoglu, C. Baycu, Protective effects of zinc on testes of cadmium-treated rats, Bull. Environ. Contam. Toxicol. 81 (6) (2008) $521-524$.

[103] S. Amara, H. Abdelmelek, C. Garrel, P. Guiraud, T. Douki, J.L. Ravanat, A. Favier, M. Sakly, K. Ben Rhouma, Preventive effect of zinc against cadmium- induced oxidative stress in the rat testis, J. Reprod. Dev, 54 (2) (2008) $129-134$

[104] U. Ahsan, Z. Kamran, I. Raza, S. Ahmad, W. Babar, M.H. Riaz, Z. Iqbal, Role of selenium in male reproduction - a review, Anim. Reprod. Sci. 146 (1-2) (2014) 55-62.

[105] N. Kaushal, M.P. Bansal, Diminished reproductive potential of male mice in response to selenium-induced oxidative stress: involvement of HSP70, HSP 70-2, and MSJ-1, J. Biochem. Mol. Toxicol. 23 (2) (2009) 125-136.

[106] J. Marin-Guzman, D.C. Mahan, R. Whitmoyer, Effect of dietary selenium and vitamin E on the ultrastructure and ATP concentration of boar spermatozoa, and the efficacy of added sodium selenite in extended semen on sperm motility, J. Anim. Sci. 78 (6) (2000) 1544-1550

[107] G.E. Olson, V.P. Winfrey, S.K. Nagdas, K.E. Hill, R.F. Burk, Selenoprotein P is required for mouse sperm development, Biol. Reprod. 73 (1) (2005) 201-211.

[108] S. Shalini, M.P. Bansal, Dietary selenium deficiency as well as excess supplementation induces multiple defects in mouse epididymal spermatozoa: understanding the role of selenium in male fertility, Int. J. Androl. 31 (4) (2008) 438-449.

[109] D. Behne, H. Weiler, A. Kyriakopoulos, Effects of selenium deficiency on testicular morphology and function in rats, J. Reprod. Fertil. 106 (2) (1996) 291-297.

[110] A.S. Wu, J.E. Oldfield, L.R. Shull, P.R. Cheeke, Specific effect of selenium deficiency on rat sperm, Biol. Reprod. 20 (4) (1979) 793-798.

[111] R. Kaur, K. Kaur, Effects of dietary selenium (SE) on morphology of testis and cauda epididymis in rats, Indian J. Physiol. Pharmacol. 44 (3) (2000) 265-272.

[112] S. Turk, R. Mandar, R. Mahlapuu, A. Viitak, M. Punab, T. Kullisaar, Male infertility: decreased levels of selenium, zinc and antioxidants, J. Trace Ele. Med. Biol. Organ Soc. Miner. Trace Ele. 28 (2) (2014) 179-185.

[113] G. Bleau, J. Lemarbre, G. Faucher, K.D. Roberts, A. Chapdelaine, Semen selenium and human fertility, Fertil. Steril. 42 (6) (1984) 890-894.

[114] M. Saaranen, U. Suistomaa, M. Kantola, S. Saarikoski, T. Vanha-Perttula, Lead, magnesium, selenium and zinc in human seminal fluid: comparison with semen parameters and fertility, Hum. Reprod. 2 (6) (1987) 475-479.

[115] A.C. Roy, R. Karunanithy, S.S. Ratnam, Lack of correlation of selenium level in human semen with sperm count/motility, Arch. Androl. 25 (1) (1990) 59-62.

[116] A.G. Abdel Rahim, J.R. Arthur, C.F. Mills, Effects of dietary copper, cadmium, iron, molybdenum and manganese on selenium utilization by the rat, J. Nutr. 116 (3) (1986) 403-411.

[117] L. Wang, X. Zhou, D. Yang, Z. Wang, Effects of lead and/or cadmium on the distribution patterns of some essential trace elements in immature female rats, Hum. Exp. Toxicol. 30 (12) (2011) 1914-1923.

[118] H. Ohta, S. Imamiya, H. Yoshikawa, [The protective effect of simultaneous selenium administration on acute cadmium toxicity and metallothionein]: Sangyo igaku, Jpn. J. Ind. Health 30 (6) (1988) 451-458.

[119] R.W. Chen, P.D. Whanger, P.H. Weswig, Selenium - induced redistribution of cadmium binding to tissue proteins: a possible mechanism of protection against cadmium toxicity, Bioinorg. Chem. 4 (2) (1975) 125-133.

[120] P.D. Whanger, Cadmium effects in rats on tissue iron, selenium, and blood pressure; blood and hair cadmium in some oregon residents, Environ. Health Perspect. 28 (1979) 115-121.

[121] Z.Z. Wahba, T.P. Coogan, S.W. Rhodes, M.P. Waalkes, Protective effects of selenium on cadmium toxicity in rats: role of altered toxicokinetics and metallothionein, J. Toxicol. Environ. Health 38 (2) (1993) 171-182.

[122] S.A. Gunn, T.C. Gould, W.A. Anderson, Mechanisms of zinc, cysteine and selenium protection against cadmium induced vascular injury to mouse testis, J. Reprod. Fertil. 15 (1) (1968) 65-70.

[123] R.J. Niewenhuis, P.L. Fende, The protective effect of selenium on cadmium-induced injury to normal and cryptorchid testes in the rat, Biol. Reprod. 19 (1) (1978) 1-7

[124] N. Sugawara, Y. Hirohata, C. Sugawara, Testicular dysfunction induced by cadmium and its improvement caused by selenium in the mouse, J. Env. Pathol. Toxicol. Oncol. Off. Organ Int. Soc. Environ. Toxicol. Cancer 9 (1) (1989) 53-64

[125] M. Katakura, N. Sugawara, [Preventive effect of selenium against the testicular injury by cadmium]: Nihon eiseigaku zasshi, Jpn. J. Hyg. 54 (2) (1999) 481-489.

[126] A.W. Obianime, I.I. Roberts, Antioxidants, cadmium-induced toxicity, serum biochemical and the histological abnormalities of the kidney and testes of the male Wistar rats, Niger. J. Physiol. Sci. Off. Publ. Physiol. Soc. Niger. 24 (2) (2009) 177-185

[127] S.H. Bekheet, Comparative effects of repeated administration of cadmium chloride during pregnancy and lactation and selenium protection against cadmium toxicity on some organs in immature rats' offsprings, Biol. Trace Elem. Res. 144 (1-3) (2011) 1008-1023.

[128] X.M. Ren, G.G. Wang, D.Q. Xu, K. Luo, Y.X. Liu, Y.H. Zhong, Y.Q. Cai, The protection of selenium on cadmium-induced inhibition of spermatogenesis via activating testosterone synthesis in mice, Food Chem. Toxicol. 50 (10) (2012) 3521-3529.

[129] S.A. El-Maraghy, N.N. Nassar, Modulatory effects of lipoic acid and selenium against cadmium-induced biochemical alterations in testicular steroidogenesis, J. Biochem. Mol. Toxicol. 25 (1) (2011) 15-25.

[130] N. Sugawara, K. Koike, K. Taguchi, T. Tsukakubo, T. Nihei, Y. Yoshida, H. Wada, H. Miyake, Time dependent effects of selenium on cadmium-induced 
acute mouse testicular damage, J. Toxicol. Sci. 11 (4) (1986) 303-312.

[131] N.S. Alabi, P.D. Whanger, A.S. Wu, Interactive effects of organic and inorganic selenium with cadmium and mercury on spermatozoal oxygen consumption and motility in vitro, Biol. Reprod. 33 (4) (1985) 911-919.

[132] S.T. Omaye, A.L. Tappel, Effect of cadmium chloride on the rat testicular soluble selenoenzyme, glutathione peroxidase, Res. Commun. Chem. Pathol. Pharmacol. 12 (4) (1975) 695-711.

[133] N. Sugawara, C. Sugawara, Selenium protection against testicular lipid peroxidation from cadmium, J. Appl. Biochem. 6 (4) (1984) 199-204.

[134] J.L. Li, R. Gao, S. Li, J.T. Wang, Z.X. Tang, S.W. Xu, Testicular toxicity induced by dietary cadmium in cocks and ameliorative effect by selenium, Biomet. Int. J. Role Met. Ions Biol. Biochem. Med. 23 (4) (2010) 695-705.

[135] S.O. Abarikwu, B.O. Iserhienrhien, T.A. Badejo, Rutin- and selenium-attenuated cadmium-induced testicular pathophysiology in rats, Hum. Exp. Toxicol. 32 (4) (2013) 395-406.

[136] S.J. Yiin, C.L. Chern, J.Y. Sheu, T.H. Lin, Cadmium induced lipid peroxidation in rat testes and protection by selenium, Biomet. Int. J. Role Met. Ions Biol. Biochem. Med. 12 (4) (1999) 353-359.

[137] S. Dodig, I. Cepelak, The facts and controversies about selenium, Acta Pharm. 54 (4) (2004) 261-276.

[138] L. Flohe, W.A. Gunzler, H.H. Schock, Glutathione peroxidase: a selenoenzyme, FEBS Lett. 32 (1) (1973) 132-134.

[139] R.F. Burk, K.E. Hill, J.A. Awad, J.D. Morrow, P.R. Lyons, Liver and kidney necrosis in selenium-deficient rats depleted of glutathione, Laboratory investigation, J. Tech. Methods Pathol. 72 (6) (1995) 723-730.

[140] H. Tapiero, D.M. Townsend, K.D. Tew, The antioxidant role of selenium and seleno-compounds, Biomed. Pharmacother. $=$ Biomedecine Pharmacotherapie 57 (3-4) (2003) 134-144.

[141] S.J. Stohs, D. Bagchi, Oxidative mechanisms in the toxicity of metal ions, Free Radic. Biol. Med. 18 (2) (1995) 321-336.

[142] M. Valko, H. Morris, M.T. Cronin, Metals, toxicity and oxidative stress, Curr. Med. Chem. 12 (10) (2005) 1161-1208.

[143] B. Migliarini, A.M. Campisi, F. Maradonna, C. Truzzi, A. Annibaldi, G. Scarponi, O. Carnevali, Effects of cadmium exposure on testis apoptosis in the marine teleost Gobius niger, Gen. Comp. Endocrinol. 142 (1-2) (2005) 241-247.

[144] L. Wang, T. Xu, W.W. Lei, D.M. Liu, Y.J. Li, R.J. Xuan, J.J. Ma, Cadmium-induced oxidative stress and apoptotic changes in the testis of freshwater crab, Sinopotamon henanense, PLoS One 6 (11) (2011) e27853.

[145] A. Pillai, S. Gupta, Antioxidant enzyme activity and lipid peroxidation in liver of female rats co-exposed to lead and cadmium: effects of vitamin $\mathrm{E}$ and Mn2+, Free Radic. Res. 39 (7) (2005) 707-712.

[146] M.S. Yang, K.P. Lai, K.Y. Cheng, C.K. Wong, Changes in endogenous Zn and Cu distribution in different cytosolic protein fractions in mouse liver after administration of a single sublethal dose of $\mathrm{CdCl}(2)$, Toxicology 154 (1-3) (2000) 103-111.

[147] P.M. Hanna, R.P. Mason, Direct evidence for inhibition of free radical formation from $\mathrm{Cu}(\mathrm{I})$ and hydrogen peroxide by glutathione and other potential ligands using the EPR spin-trapping technique, Arch. Biochem. Biophys. 295 (1) (1992) 205-213.

[148] I. Dreher, C. Schmutzler, F. Jakob, J. Kohrle, Expression of selenoproteins in various rat and human tissues and cell lines, J. Trace Ele. Med. Biol. Organ Soc. Miner. Trace Ele. 11 (2) (1997) 83-91.

[149] C. Foresta, L. Flohe, A. Garolla, A. Roveri, F. Ursini, M. Maiorino, Male fertility is linked to the selenoprotein phospholipid hydroperoxide glutathione peroxidase, Biol. Reprod. 67 (3) (2002) 967-971.

[150] I. Messaoudi, M. Banni, L. Said, K. Said, A. Kerkeni, Involvement of selenoprotein P and GPx4 gene expression in cadmium- induced testicular pathophysiology in rat, Chem. Biol. Interact. 188 (1) (2010) 94-101.

[151] L. Said, M. Banni, A. Kerkeni, K. Said, I. Messaoudi, Influence of combined treatment with zinc and selenium on cadmium induced testicular pathophysiology in rat, Food Chem. Toxicol. 48 (10) (2010) 2759-2765.

[152] T. Koizumi, Z.G. Li, Role of oxidative stress in single-dose, cadmium-induced testicular cancer, J. Toxicol. Environ. Health 37 (1) (1992) 25-36.

[153] A. Selypes, P. Serenyi, I. Boldog, F. Bokros, S. Takacs, Acute and long-term genotoxic effects of $\mathrm{CdCl} 2$ on testes of mice, J. Toxicol. Environ. Health 36 (4) (1992) 401-409.

[154] H. Oliveira, M. Spano, C. Santos, L. Pereira Mde, Adverse effects of cadmium exposure on mouse sperm, Reprod. Toxicol. 28 (4) (2009) 550-555.

[155] R. Jones, T. Mann, R. Sherins, Peroxidative breakdown of phospholipids in human spermatozoa, spermicidal properties of fatty acid peroxides, and protective action of seminal plasma, Fertil. Steril. 31 (5) (1979) 531-537.

[156] S. Kothari, A. Thompson, A. Agarwal, S.S. du Plessis, Free radicals: their beneficial and detrimental effects on sperm function, Indian J. Exp. Biol. 48 (5) (2010) 425-435.

[157] K. Tremellen, Oxidative stress and male infertility-a clinical perspective, Hum. Reprod. Update 14 (3) (2008) 243-258.

[158] R.J. Aitken, A.J. Koppers, Apoptosis and DNA damage in human spermatozoa, Asian J. Androl. 13 (1) (2011) 36-42.

[159] M. Arabi, A.A. Mohammadpour, Adverse effects of cadmium on bull spermatozoa, Vet. Res. Commun. 30 (8) (2006) 943-951.

[160] D. Ma, Y. Hou, L. Du, N. Li, R. Xuan, F. Wang, W. Jing, L. Wang, Oxidative damages and ultrastructural changes in the sperm of freshwater crab Sinopotamon henanense exposed to cadmium, Ecotoxicol. Environ. Saf. 98 (2013) 244-249.
[161] S. Roychoudhury, P. Massanyi, J. Bulla, M.D. Choudhury, N. Lukac, T. Filipejova, J. Trandzik, R. Toman, V. Almasiova, Cadmium toxicity at low concentration on rabbit spermatozoa motility, morphology and membrane integrity in vitro, J. Environ. Sci. Health Part A Tox. Hazard. Subst. Environ. Eng. 45 (11) (2010) 1374-1383.

[162] S. Selvaraju, S. Nandi, P.S. Gupta, J.P. Ravindra, Effects of heavy metals and pesticides on buffalo (Bubalus bubalis) spermatozoa functions in vitro, Reprod. Domest. Anim. = Zuchthygiene 46 (5) (2011) 807-813.

[163] E. Tvrda, Z. Knazicka, J. Lukacova, M. Schneidgenova, Z. Goc, A. Gren, C. Szabo, P. Massanyi, N. Lukac, The impact of lead and cadmium on selected motility, prooxidant and antioxidant parameters of bovine seminal plasma and spermatozoa, J. Environ. Sci. Health Part A Tox. Hazard. Subst. Environ. Eng. 48 (10) (2013) 1292-1300.

[164] M. Filipic, T.K. Hei, Mutagenicity of cadmium in mammalian cells: implication of oxidative DNA damage, Mutat. Res. 546 (1-2) (2004) 81-91.

[165] P.D. Ray, A. Yosim, R.C. Fry, Incorporating epigenetic data into the risk assessment process for the toxic metals arsenic, cadmium, chromium, lead, and mercury: strategies and challenges, Front. Genet. 5 (2014) 201.

[166] A. Ruiz-Hernandez, C.C. Kuo, P. Rentero-Garrido, W.Y. Tang, J. Redon, J.M. Ordovas, A. Navas-Acien, M. Tellez-Plaza, Environmental chemicals and DNA methylation in adults: a systematic review of the epidemiologic evidence, Clin. Epigenet. 7 (1) (2015) 55.

[167] N. Vilahur, M. Vahter, K. Broberg, The epigenetic effects of prenatal cadmium exposure, Curr. Environ. Health Rep. 2 (2) (2015) 195-203.

[168] B. Wang, Y. Li, C. Shao, Y. Tan, L. Cai, Cadmium and its epigenetic effects, Curr. Med. Chem. 19 (16) (2012) 2611-2620.

[169] C. Xiao, Y. Liu, C. Xie, W. Tu, Y. Xia, M. Costa, X. Zhou, Cadmium induces histone $\mathrm{H} 3$ lysine methylation by inhibiting histone demethylase activity, Toxicol. Sci. 145 (1) (2015) 80-89.

[170] G.L. Grice, J.A. Nathan, The recognition of ubiquitinated proteins by the proteasome, Cell. Mol. Life Sci. CMLS 73 (September 18)(2016) 3497-3506.

[171] P. Sutovsky, Ubiquitin-dependent proteolysis in mammalian spermatogenesis, fertilization, and sperm quality control: killing three birds with one stone, Microsc. Res. Tech. 61 (1) (2003) 88-102.

[172] P. Sutovsky, R. Moreno, J. Ramalho-Santos, T. Dominko, W.E. Thompson, G. Schatten, A putative, ubiquitin-dependent mechanism for the recognition and elimination of defective spermatozoa in the mammalian epididymis, J. Cell Sci. 114 (Pt 9) (2001) 1665-1675.

[173] X. Yu, S. Hong, E.M. Faustman, Cadmium-induced activation of stress signaling pathways, disruption of ubiquitin-dependent protein degradation and apoptosis in primary rat Sertoli cell-gonocyte cocultures, Toxicol. Sci. 104 (2) (2008) 385-396.

[174] D. Beyersmann, S. Hechtenberg, Cadmium, gene regulation, and cellular signalling in mammalian cells, Toxicol. Appl. Pharmacol. 144 (2) (1997) 247-261.

[175] A. Martelli, E. Rousselet, C. Dycke, A. Bouron, J.M. Moulis, Cadmium toxicity in animal cells by interference with essential metals, Biochimie 88 (11) (2006) 1807-1814.

[176] S. Benoff, L.O. Goodwin, C. Millan, I.R. Hurley, R.G. Pergolizzi, J.L. Marmar, Deletions in L-type calcium channel alpha1 subunit testicular transcripts correlate with testicular cadmium and apoptosis in infertile men with varicoceles, Fertil. Steril. 83 (3) (2005) 622-634.

[177] R. Felix, Molecular physiology and pathology of Ca2+-conducting channels in the plasma membrane of mammalian sperm, Reproduction 129 (3) (2005) 251-262.

[178] B.M. Sanborn, J.J. Heindel, G.A. Robison, The role of cyclic nucleotides in reproductive processes, Annu. Rev. Physiol. 42 (1980) 37-57.

[179] A.M. Hofer, Interactions between calcium and cAMP signaling, Curr. Med. Chem. 19 (34) (2012) 5768-5773.

[180] W.Y. Cheung, Calmodulin and its activation by cadmium ion, Ann. N. Y. Acad. Sci. 522 (1988) 74-87.

[181] R.J. Niewenhuis, W.C. Prozialeck, Calmodulin inhibitors protect against cadmium-induced testicular damage in mice, Biol. Reprod. 37 (1) (1987) 127-133.

[182] N. Shiraishi, S. Rehm, M.P. Waalkes, Effect of chlorpromazine pretreatment on cadmium toxicity in the male Wistar (WF/NCr) rat, J. Toxicol. Environ. Health 42 (2) (1994) 193-208.

[183] L.J. Martin, H. Chen, X. Liao, H. Allayee, D.M. Shih, G.S. Lee, D.N. Hovland Jr., W.A. Robbins, K. Carnes, R.A. Hess, A.J. Lusis, M.D. Collins, FK506, a calcineurin inhibitor, prevents cadmium-induced testicular toxicity in mice, Toxicol. Sci. 100 (2) (2007) 474-485.

[184] J.Y. Park, H.J. Ahn, J.G. Gu, K.H. Lee, J.S. Kim, H.W. Kang, J.H. Lee, Molecular identification of Ca2+ channels in human sperm, Exp. Mol. Med. 35 (4) (2003) 285-292.

[185] W.Y. Son, J.H. Lee, J.H. Lee, C.T. Han, Acrosome reaction of human spermatozoa is mainly mediated by alpha1H T-type calcium channels, Mol. Hum. Reprod. 6 (10) (2000) 893-897.

[186] L. Li, J.H. Liu, J.G. Li, Z.Q. Ye, X.L. Wang, [Molecular identification of Ca2+ channels in human ejaculated sperm], Zhonghua nan ke xue = Nat. J. Androl. 12 (10) (2006) 910-912.

[187] C.M. O’Toole, E.R. Roldan, L.R. Fraser, Role for Ca2+ channels in the signal transduction pathway leading to acrosomal exocytosis in human spermatozoa, Mol. Reprod. Dev. 45 (2) (1996) 204-211.

[188] S. Benoff, Voltage dependent calcium channels in mammalian spermatozoa, ABBV Front Biosci. 3 (1998) D1220-40. 
[189] L.O. Goodwin, D.S. Karabinus, R.G. Pergolizzi, S. Benoff, L-type voltage-dependent calcium channel alpha-1C subunit mRNA is present in ejaculated human spermatozoa, Mol. Hum. Reprod. 6 (2) (2000) 127-136.

[190] L.O. Goodwin, N.B. Leeds, I. Hurley, F.S. Mandel, R.G. Pergolizzi, S. Benoff, Isolation and characterization of the primary structure of testis-specific L-type calcium channel: implications for contraception, Mol. Hum. Reprod. 3 (3) (1997) 255-268.

[191] L. Li, J. Liu, J. Li, Z. Ye, Pharmacological investigation of voltage-dependent $\mathrm{Ca} 2+$ channels in human ejaculatory sperm in vitro, J. Huazhong Univ. Sci. Technol. 26 (5) (2006) 607-609 (Medical sciences = Hua zhong ke ji da xue bao. Yi xue Ying De wen ban=Huazhong keji daxue xuebao. Yixue Yingdewen ban).

[192] T. Kiss, O.N. Osipenko, Toxic effects of heavy metals on ionic channels Pharmacol. Rev. 46 (3) (1994) 245-267.

[193] P.M. Hinkle, E.D. Shanshala, 2nd, E.J. Nelson, Measurement of intracellular cadmium with fluorescent dyes. Further evidence for the role of calcium channels in cadmium uptake, J. Biol. Chem. 267 (35) (1992) 25553-25559.

[194] R.E. Westenbroek, D.F. Babcock, Discrete regional distributions suggest diverse functional roles of calcium channel alpha1 subunits in sperm, Dev. Biol. 207 (2) (1999) 457-469.

[195] C.L. Trevino, R. Felix, L.E. Castellano, C. Gutierrez, D. Rodriguez, J. Pacheco, I. Lopez-Gonzalez, J.C. Gomora, V. Tsutsumi, A. Hernandez- Cruz, T. Fiordelisio, A.L. Scaling, A. Darszon, Expression and differential cell distribution of low-threshold $\mathrm{Ca}(2+)$ channels in mammalian male germ cells and sperm, FEBS Lett. 563 (1-3) (2004) 87-92.

[196] U. Kanwar, R.J. Anand, S.N. Sanyal, The effect of nifedipine, a calcium channel blocker, on human spermatozoal functions, Contraception 48 (5) (1993) 453-470.

[197] R.J. Anand, U. Kanwar, S.N. Sanyal, Calcium channel antagonist verapamil modulates human spermatozoal functions: research in experimental medicine, Zeitschrift fur die gesamte experimentelle Medizin einschliesslich experimenteller Chirurgie 194 (3) (1994) 165-178.

[198] D. Gunnarsson, G. Nordberg, P. Lundgren, G. Selstam, Cadmium-induced decrement of the $\mathrm{LH}$ receptor expression and cAMP levels in the testis of rats, Toxicology $183(1-3)(2003)$ 57-63.

[199] R.L. Singhal, Z. Merali, P.D. Hrdina, Aspects of the biochemical toxicology of cadmium, Fed. Proc. 35 (1) (1976) 75-80.

[200] F. Thevenod, Cadmium and cellular signaling cascades: to be or not to be? Toxicol. Appl. Pharmacol. 238 (3) (2009) 221-239.

[201] K. Breving, A. Esquela-Kerscher, The complexities of microRNA regulation: mirandering around the rules, Int. J. Biochem. Cell Biol. 42 (8) (2010) $1316-1329$

[202] J. Brocato, M. Costa, Basic mechanics of DNA methylation and the unique landscape of the DNA methylome in metal-induced carcinogenesis, Crit. Rev. Toxicol. 43 (6) (2013) 493-514.

[203] T. Kouzarides, Chromatin modifications and their function, Cell 128 (4) (2007) 693-705

[204] D.T. Carrell, S.S. Hammoud, The human sperm epigenome and its potential role in embryonic development, Mol. Hum. Reprod. 16 (1) (2010) 37-47.

[205] S. Houshdaran, V.K. Cortessis, K. Siegmund, A. Yang, P.W. Laird, R.Z. Sokol, Widespread epigenetic abnormalities suggest a broad DNA methylation erasure defect in abnormal human sperm, PLoS One 2 (12)(2007) e1289.

[206] M. Tian, H. Bao, F.L. Martin, J. Zhang, L. Liu, Q. Huang, H. Shen, Association of DNA methylation and mitochondrial DNA copy number with human semen quality, Biol. Reprod. 91 (4) (2014) 101

[207] K.I. Aston, V. Punj, L. Liu, D.T. Carrell, Genome-wide sperm deoxyribonucleic acid methylation is altered in some men with abnormal chromatin packaging or poor in vitro fertilization embryogenesis, Fertil. Steril. 97 (2) (2012) 285-292

[208] C.J. Marques, F. Carvalho, M. Sousa, A. Barros, Genomic imprinting in disruptive spermatogenesis, Lancet 363 (9422) (2004) 1700-1702.

[209] C.J. Marques, P. Costa, B. Vaz, F. Carvalho, S. Fernandes, A. Barros, M. Sousa, Abnormal methylation of imprinted genes in human sperm is associated with oligozoospermia, Mol. Hum. Reprod. 14 (2) (2008) 67-74.

[210] H. Kobayashi, A. Sato, E. Otsu, H. Hiura, C. Tomatsu, T. Utsunomiya, H. Sasaki, N. Yaegashi, T. Arima, Aberrant DNA methylation of imprinted loci in sperm from oligospermic patients, Hum. Mol. Genet. 16 (21) (2007) 2542-2551.

[211] S.S. Hammoud, J. Purwar, C. Pflueger, B.R. Cairns, D.T. Carrell, Alterations in sperm DNA methylation patterns at imprinted loci in two classes of infertility, Fertil. Steril. 94 (5) (2010) 1728-1733.

[212] C.C. Boissonnas, H.E. Abdalaoui, V. Haelewyn, P. Fauque, J.M. Dupont, I. Gut, D. Vaiman, P. Jouannet, J. Tost, H. Jammes, Specific epigenetic alterations of IGF2-H19 locus in spermatozoa from infertile men, Eur. J. Hum. Genet. EJHG 18 (1) (2010) 73-80.

[213] A. Poplinski, F. Tuttelmann, D. Kanber, B. Horsthemke, J. Gromoll, Idiopathic male infertility is strongly associated with aberrant methylation of MEST and IGF2/H19 ICR1, Int. J. Androl. 33 (4) (2010) 642-649.

[214] A. Minor, V. Chow, S. Ma, Aberrant DNA methylation at imprinted genes in testicular sperm retrieved from men with obstructive azoospermia and undergoing vasectomy reversal, Reproduction 141 (6) (2011) 749-757.

[215] M. Takiguchi, W.E. Achanzar, W. Qu, G. Li, M.P. Waalkes, Effects of cadmium on DNA-(Cytosine-5) methyltransferase activity and DNA methylation status during cadmium-induced cellular transformation, Exp. Cell Res. 286 (2) (2003) 355-365.
[216] H. Zhu, K. Li, J. Liang, J. Zhang, Q. Wu, Changes in the levels of DNA methylation in testis and liver of SD rats neonatally exposed to 5-aza-2'-deoxycytidine and cadmium, J. Appl. Toxicol. JAT 31 (5) (2011) 484-495.

[217] K.Y. Li, W.S. Xiao, Q. Wu, X.L. Chang, Z.J. Zhou, J. Zhang, D.Q. Su, [Effect of neonatal exposure to environmental pollutants on the DNA methylation of rat testis], Zhonghua lao dong wei sheng zhi ye bing za zhi = Zhonghua laodong weisheng zhiyebing zazhi = Chin. J. Ind. Hyg. Occup. Dis. 27 (11) (2009) 649-654.

[218] K.P. Singh, R. Kumari, C. Pevey, D. Jackson, J.W. DuMond, Long duration exposure to cadmium leads to increased cell survival, decreased DNA repair capacity, and genomic instability in mouse testicular Leydig cells, Cancer Lett. 279 (1) (2009) 84-92.

[219] A.F. Mohanty, F.M. Farin, T.K. Bammler, J.W. MacDonald, Z. Afsharinejad, T.M. Burbacher, D.S. Siscovick, M.A. Williams, D.A. Enquobahrie, Infant sex-specific placental cadmium and DNA methylation associations, Environ. Res. 138 (2015) 74-81.

[220] S. Virani, K.M. Rentschler, M. Nishijo, W. Ruangyuttikarn, W. Swaddiwudhipong, N. Basu, L.S. Rozek, DNA methylation is differentially associated with environmental cadmium exposure based on sex and smoking status, Chemosphere 145 (2016) 284-290.

[221] M. Kippler, K. Engstrom, S.J. Mlakar, M. Bottai, S. Ahmed, M.B. Hossain, R. Raqib, M. Vahter, K. Broberg, Sex-specific effects of early life cadmium exposure on DNA methylation and implications for birth weight Epigenetics 8 (5) (2013) 494-503.

[222] A. Lafuente, The hypothalamic-pituitary-gonadal axis is target of cadmium toxicity. An update of recent studies and potential therapeutic approaches, Food Chem. Toxicol. 59 (2013) 395-404.

[223] A. Stoica, B.S. Katzenellenbogen, M.B. Martin, Activation of estrogen receptor-alpha by the heavy metal cadmium, Mol. Endocrinol. 14 (4) (2000) 545-553.

[224] P. Garcia-Morales, M. Saceda, N. Kenney, N. Kim, D.S. Salomon, M.M. Gottardis, H.B. Solomon, P.F. Sholler, V.C. Jordan, M.B. Martin, Effect of cadmium on estrogen receptor levels and estrogen-induced responses in human breast cancer cells, J. Biol. Chem. 269 (24) (1994) 16896-16901.

[225] M. Brama, L. Gnessi, S. Basciani, N. Cerulli, L. Politi, G. Spera, S. Mariani, S Cherubini, A. Scotto d'Abusco, R. Scandurra, S. Migliaccio, Cadmium induces mitogenic signaling in breast cancer cell by an ERalpha-dependent mechanism, Mol. Cell. Endocrinol. 264 (1-2) (2007) 102-108.

[226] Z. Liu, X. Yu, Z.A. Shaikh, Rapid activation of ERK1/2 and AKT in human breast cancer cells by cadmium, Toxicol. Appl. Pharmacol. 228 (3) (2008) 286-294.

[227] M.D. Johnson, N. Kenney, A. Stoica, L. Hilakivi-Clarke, B. Singh, G. Chepko, R. Clarke, P.F. Sholler, A.A. Lirio, C. Foss, R. Reiter, B. Trock, S. Paik, M.B. Martin, Cadmium mimics the in vivo effects of estrogen in the uterus and mammary gland, Nat. Med. 9 (8) (2003) 1081-1084.

[228] M.B. Martin, H.J. Voeller, E.P. Gelmann, J. Lu, E.G. Stoica, E.J. Hebert, R. Reiter, B. Singh, M. Danielsen, E. Pentecost, A. Stoica, Role of cadmium in the regulation of AR gene expression and activity, Endocrinology 143 (1) (2002) 263-275.

[229] A.J. Visser, J.N. Deklerk, The effect of dietary cadmium on prostate growth, Trans. Am. Assoc. Genitourin. Surg. 70 (1978) 66-68.

[230] D. Gunnarsson, G. Nordberg, G. Selstam, Differential effects of cadmium on the gene expression of seven-transmembrane-spanning receptors and GAPDH in the rat testis, Toxicol. Lett. 168 (1) (2007) 51-57.

[231] A. Lafuente, N. Marquez, M. Perez-Lorenzo, D. Pazo, A.I. Esquifino, Cadmium effects on hypothalamic-pituitary-testicular axis in male rats, Exp. Biol. Med. 226 (6) (2001) 605-611.

[232] A. Lafuente, P. Cano, A. Esquifino, Are cadmium effects on plasma gonadotropins, prolactin, ACTH, GH and TSH levels, dose-dependent? Biomet. Int. J. Role Metal Ions Biol. Biochem. Med. 16 (2) (2003) 243-250.

[233] J.H. Kagi, A. Schaffer, Biochemistry of metallothionein, Biochemistry 27 (23) (1988) 8509-8515.

[234] C.D. Klaassen, J. Liu, S. Choudhuri, Metallothionein: an intracellular protein to protect against cadmium toxicity, Annu. Rev. Pharmacool. Toxicol. 39 (1999) 267-294.

[235] P.L. Goering, C.D. Klaassen, Altered subcellular distribution of cadmium following cadmium pretreatment: possible mechanism of tolerance to cadmium-induced lethality, Toxicol. Appl. Pharmacol. 70 (2) (1983) 195-203.

[236] M.R. Bhave, M.J. Wilson, M.P. Waalkes, Methylation status and organization of the metallothionein-I gene in livers and testes of strains of mice resistant and susceptible to cadmium, Toxicology 50 (3) (1988) 231-245.

[237] L.C. Xu, H. Sun, S.Y. Wang, L. Song, H.C. Chang, X.R. Wang, The roles of metallothionein on cadmium-induced testes damages in Sprague- Dawley rats, Environ. Toxicol. Pharmacol. 20 (1) (2005) 83-87.

[238] J. Liu, C. Corton, D.J. Dix, Y. Liu, M.P. Waalkes, C.D. Klaassen, Genetic background but not metallothionein phenotype dictates sensitivity to cadmium-induced testicular injury in mice, Toxicol. Appl. Pharmacol. 176 (1) (2001) 1-9.

[239] H. Fujishiro, S. Okugaki, S. Yasumitsu, S. Enomoto, S. Himeno, Involvement of DNA hypermethylation in down-regulation of the zinc transporter ZIP8 in cadmium-resistant metallothionein-null cells, Toxicol. Appl. Pharmacol. 241 (2) (2009) 195-201. 